\title{
Restrain Price Collusion in Trade-Based Supply Chain Finance
}

\author{
Qiang Wei $\mathbb{D},{ }^{1}$ Xinyu Gou, ${ }^{2}$ Tianyu Deng, ${ }^{3}$ and Chunguang Bai $\mathbb{D}^{1}$ \\ ${ }^{1}$ School of Management and Economics, University of Electronic Science and Technology of China, Chengdu, 611731, China \\ ${ }^{2}$ School of Business Administration, Southwestern University of Finance and Economics, Chengdu, 611130, China \\ ${ }^{3}$ Business School, Southwest Minzu University, Chengdu, 610041, China
}

Correspondence should be addressed to Chunguang Bai; cbai@uestc.edu.cn

Received 24 February 2021; Accepted 6 May 2021; Published 8 June 2021

Academic Editor: Baogui Xin

Copyright (c) 2021 Qiang Wei et al. This is an open access article distributed under the Creative Commons Attribution License, which permits unrestricted use, distribution, and reproduction in any medium, provided the original work is properly cited.

\begin{abstract}
Collusion can increase the transaction value among supply chain members to obtain higher loans from supply chain finance (SCF) service provider, which will bring some serious risks for SCF. However, it is difficult to be identified and restrain the SCF service provider due to its stability and hiddenness. Different SCF transaction structures will affect the profits of supply chain members from collusion. This paper develops various game models for collusion and not collusion for different SCF transaction structures and investigates the impact of SCF transaction structures on the boundary conditions of collusion. Through comparative analysis, the findings of models are as follows: (1) in a two-echelon supply chain, the supplier and retailer are more likely to conduct collusion under the sequential game than under the simultaneous game; (2) collusion in the two-echelon supply chain can obtain higher loans than that in the three-echelon supply chain, so it has more serious hidden danger; (3) in the two-echelon supply chain, collusion is easier to form than in the three-echelon SCF supply chain that has spontaneous endogenous constraints. We also develop two types of mechanisms to restrain collusion behavior from profit sharing and incomplete information perspectives. Finally, we summarize the theoretical implications and analyze the management implications through a case study.
\end{abstract}

\section{Introduction}

Collusion refers to the behavior that some firms reach a secret agreement on the price or volume of the products or services they provided and use the agreed price to replace the market price, so as to obtain more profits $[1,2]$. Once collusion is implemented, it will inevitably lead to the loss of the profits of consumers and other firms, that is, they will pay higher prices for products and services. Although governments have enacted antitrust laws (such as the antitrust law of China in 2007) to limit the formation of cartels and other collusions in determining market price, collusion is still frequently appeared in the market $[1,3]$. One reason is that it is very difficult to obtain concrete evidence to prove collusion behavior between firms [4]. Another reason is that firms of collusion can achieve extra profits, such as high financial loans.

The rapid development of supply chain finance (SCF) has effectively solved the problem of the capital shortage of supply chain firms and promoted the development of real economic and financial services [5]. Although the SCF system has set up many mechanisms to prevent various financial risks, collusion brings great risks to SCF service provider because of its hiddenness. For example, more than 20 steel traders increased the price and amount of transactions through collusion in China to obtain higher financial loans based on the transaction value and were sued by the bank to the court (see [6]). The amount of cash and the number of companies involved are unprecedented. For another example, on April 2, 2020, Luckin Coffee Inc. (NASDAQ: LK) announced that the $\mathrm{COO}$ and several other executives engaged in certain misconduct, including fabricating certain transactions amounting to roughly RMB 2.2 billion, resulting in the stock plunging by $80 \%$ in one day [7]. Then, SCF service providers, such as banks, funds, and trusts, generally worry that there is no effective way to identify and prevent collusion in the financial industry. Collusion against the real trading bottom line has become a stumbling block for SCF [8]. As far as we know, there is no research on collusion in the field of SCF. 
The collusion agreement is not always unbreakable and stable. When the profit of collusion is less than that of noncollusion, the collusion agreement will be broken. SCF service providers can effectively control the profit of collusion and noncollusion through the discount factor of loans. Then, we will investigate the discount factor of loans to determine the boundary condition of collusion.

Transaction structure plays an important role in all kinds of supply chain financial loans. Previous research on SCF focuses on the design of SCF transaction structures to prevent various risks $[9,10]$. However, the impact of SCF transaction structures on the boundary condition of collusion is unclear. This paper focuses on two types of tradebased SCF transaction structures. The first is the hierarchical transaction structures, which are often divided into twoechelon supply chain and three-echelon supply chain [11]. The second is the relation structures, which are often divided into master-slave relation and equivalent relation [12]. The objective of this paper is to investigate the boundary conditions of collusion between the supply chain members in different trade-based SCF transaction structures. We mainly address the following issues:

(1) What are the boundary conditions (discount factor) (according to collusion theory in microeconomics, the boundary condition is when the discount factor is greater than a threshold, the collusion can be conducted and will be stable; otherwise, the collusion cannot be conducted and will be unstable (similar to [13]) of price collusion in these different trade-based SCF transaction structures?

(2) Which trade-based SCF transaction structure has a spontaneous endogenous constraint on collusion that is called self-restraint (not easy to collusion)? Which trade-based SCF transaction structure has hidden, unidentifiable collusion that is called hidden vulnerability (easy to collusion)?

(3) How to develop a mechanism to restrain price collusion in trade-based SCF transaction structure with hidden vulnerability from the profit sharing and incomplete information perspectives?

To answer these questions, we develop different game models for different trade-based SCF transaction structures to identify the boundary condition of collusion. We then compare and analyze the results of these boundary conditions to confirm the advantages and disadvantages of different trade-based SCF transaction structures on restraining price collusion. We look forward to providing reference values for the design of tradebased SCF transaction structure. SCFWG also points out that financial institutions are risk-averse and lack resources to evaluate numerous and varied trade-based SCF structures. In current SCF market conditions where loan quality has become a key issue, this study can provide new solutions for tradebased SCF service providers in preventing collusion and making loan decisions.

This study contributes to the operation management literature studies in the following respects. First, as far as we know, this study is the first focus on the impact of trade- based SCF transaction structures on collusion in the supply chain. Few studies have integrated collusion [14] and SCF [15] to design an effective trade-based SCF transaction structure to prevent collusion from the perspective of supply chain financial risk. Second, we also investigate the impact of the different relation structures on the collusion, such as master-slave relationship and equivalent relationship. Finally, we develop two mechanisms to restrain price collusion from profit sharing and incomplete information perspectives.

The rest of this paper is organized as follows. Section 2 reviews relevant research streams. Section 3 describes the problems. Section 4 discusses the collusion in the twoechelon supply chain, and Section 5 discusses that in the three-echelon supply chain. Section 6 conducts a comparative analysis, and Section 7 tries to extend the research, for example, profit sharing and incomplete information. Section 8 further discusses the theoretical and managerial implications. Finally, Section 9 highlights the main conclusions, limitations, and future research directions.

\section{Literature Review}

To provide research background and highlight our contributions, we mainly review two related research fields: (1) collusion in the field of economy and management and (2) SCF transaction structure.

2.1. Collusion in Economics and Management. Collusion is a kind of risk behavior in the economic field, which widely exists in insurance, financing, and other financial fields [16]. According to existing research, many different types of collusion exist, and they can be divided into two major categories, namely, management collusion and business collusion. Management collusion mainly refers to the collusion between the company's stakeholders, managers, and employees [17]. On the contrary, business collusion is complex and diverse, such as the market collusion, production collusion, and price collusion [18].

In recent years, some scholars have paid attention to collusion research in the field of operation management $[11,19,20]$. Piccolo and Reisinger. [21] analyze the impact of exclusive territories on manufacturers' incentives to sustain tacit collusion between competing supply chains. Melkonyan et al. [22] develop a formal account of virtual bargaining and demonstrate that it leads to collusion in Bertrand, but not in Cournot, competition. Zheng et al. [23] establish an infinitely repeated game to examine the interaction between the manufacturer's channel strategy and the downstream retailers' collusion behavior. Bian et al. [13] find that upstream collusion in a two-echelon supply chain is easier to sustain under Cournot competition than Bertrand competition, and it is least likely to be sustained under mixed Bertrand-Cournot competition. Miklós-Thal and Tucker [14] build a game-theoretic model to examine how better demand forecasting resulting from algorithms, machine learning, and artificial intelligence affects the sustainability of collusion in an industry. Wang et al. [24] built three two- 
tier game models: Stackelberg-collusion model, StackelbergNash model, and Stackelberg-Stackelberg model, to consider the retailers' potential collusive behavior and the upstream manufacturer's interactive decisions.

Collusion price, which differs from false price, is a collusion agreement that increases the real price consumers pay for a product and then obtains high loans from SCF service providers through the increased transaction value. Collusion also differs from the supply chain integration which realizes the maximization of supply chain benefits by positive practices, such as improving production efficiency, increasing product quality, reducing production costs, or other means $[25,26]$. However, collusion realizes the maximization of supply chain benefits by negative practices, such as increasing product price and limiting production. Then, it not only damages the benefits of consumers but also reduces the benefits of financial institutions. Supply chain integration denotes Pareto optimization, whereas collusion is the opposite [27]. Supply chain members easily make short-sighted successful decisions in collusion, thus shaking the development foundation of strategic and stable supply chain.

Collusion can increase the transaction value among supply chain members to obtain higher loans from supply chain finance (SCF) service provider, which will bring some serious risks for SCF. As collusion is very common in supply chain transactions, identifying and preventing this kind of behavior is difficult by means of policy. However, the research of price collusion in supply chain finance has not been effectively analyzed, especially in order to obtain high loans.

\subsection{Supply Chain Finance and Transaction Structure. SCF} has evolved from the original trade finance, which plays an increasingly important role in solving the financing problems of SMEs [28]. Therefore, most of the existing literature mainly studies how to design an SCF solution that can not only meet the requirements of financial institutions but also effectively solve the financing problem of SMEs, such as bill discount business [29], inventory and receivables finance [30], purchase order finance [9], supply chain inventory finance [10] and trade credit [31].

Trade finance is a very important form of SCF. Lee and Rhee [32] explain trade finance from a supplier perspective and use it as a tool for supply chain coordination. Seifert et al. [33] summarize the relevant literature of trade finance from the aspects of motivation, order quantity decision, credit period decision, and settlement period decision. They hold that trade finance can increase the number of economic orders and serve as the coordination mechanism of the supply chain. Supply chain structure and SCF have a very close relationship. Lee et al. [34] study how trade finance responds to various kinds of competition in the supply chain and the impact of trade finance on firm performance. Peura et al. [35] study whether trade finance is beneficial to suppliers in the horizontal supply chain structure.

Only when more than 20 SCF cases were heard [6] that scholars began to realize the seriousness of the SCF risk. However, at that time, few studies are about the risk management of SCF. Zhao et al. [20] use the external big dataset to establish a forecasting model from the perspective of risk management, and they predict the failures of SCF customers aiming to reduce the risk of financial institutions. They find that cooperation between logistics service providers and financial service providers seems to be a feasible method to solve the financing problem through the case analysis of Swiss Post Logistics in Hofmann's study. Martin and Hofmann [36] conduct a survey of 62 companies from Switzerland and 10 expert interviews to analyze the reasons financial service providers participate in the integrated management of the supply chain processes.

The study of SCF has three limitations though. First, collusion risk in SCF is not well studied. In recent years, the transition from the traditional rational economic man hypothesis to the behavioral economic man hypothesis has become increasingly obvious. Behavioral operation management (BOM) and behavioral finance have become new research hotspots. Therefore, SCF risk management research, as a cross-research issue of operation management and finance (OM-finance), must consider this important research foundation change. This trend has been exacerbated by the outbreak of collusion among steel traders. Second, the SCF structure has positive significance for financial loans, but the impact on collusion risk is unclear. Particularly important is the research on SCF risk management based on the behavior of all parties in the SCF transaction structure. Third, what mechanisms can prevent collusion has not been studied in detail. Song et al. [37] indicate that information sharing in supply chain and other related attributes of SMEs' supply chain network are the key factors that affect the credit quality of SMEs and influence the financing of SMEs.

\section{Problem Description}

The motivation of collusion among supply chain members is to obtain higher long profits in this paper. If the profits of collusion are high enough, supply chain members will continue to collusion. If the profits of collusion is not higher than the profits of noncollusion, then one member may form cheat behavior in collusion to obtain short-term profit of itself, thus destroying collusion agreement and returning to normal market price trading. Therefore, we need to compare the profits of collusion with the profits of cheat behavior and normal market transaction. When the profits of collusion are higher, supply chain members will choose price collusion. When the profits of price collusion are lower, supply chain members will generate cheat behavior to destroy the current collusion. As financial loans will span multiple stages of sales and production, we need to consider the profits of multiple stages and the discount value of profits. Clearly, the discount factor is the most important factor affecting the profits of collusion and noncollusion. We investigate the discount factor to determine the boundary conditions of collusion. We solve the model according to this idea.

To systematically reveal the impact of SCF transaction structures on the boundary conditions of collusion behavior, we mainly study two kinds of trade-based SCF 
transaction structures: hierarchical and relation transaction structures. The hierarchical transaction structures are often divided into a two-echelon supply chain with one supplier and one retailer (see Figure 1) and a threeechelon supply chain with one supplier, one distributor, and one retailer (see Figure 2). The relation transaction structures are often divided into master-slave relation and equivalent relation.

In the two-echelon supply chain, the retailer signs a purchase contract $(p, q)$ with the supplier. $p$ represents the unit price of the order product, whereas the $q$ represents the quantity of the order product. First, the retailer signs the financial loan contract with SCF service provider and releases the purchase order to the supplier according to the purchase contract, which is the trade flow. Second, the retailer makes a certain proportion $\hat{r}$ of loans to SCF service provider based on the value of order product between the supplier and the retailer. Third, the retailer should pay the percentage $(1-\widehat{r})$ of payments to the supplier according to the financial loan contract (see the cash flow in Figure 1). Based on the trade flow, the cash flow paid by the retailer, and confirmation information from the supplier, the SCF service provider will pay the corresponding payments $\widehat{r} \cdot p q$ to the supplier. Once the supplier receives all the payments $p q$, they will arrange to ship the order products to the retailer, which is the logistics (see Figure 1). Obviously, to get higher finance loans from the SCF service provider, the supply chain members are prone to collusion, which leads to the false increase in the transaction value of order product between the supplier and retailer.

Although only one kind of collusion exists in the twoechelon supply chain, three different types of collusion among different members exist in the three-echelon supply chain (see Figure 2). We develop various game models to identify the boundary conditions of collusion in the two-echelon supply chain and three-echelon supply chain. We also study the different boundary conditions of collusion among the master-slave relation and equivalent relation in each hierarchical transaction structure. The notation and description of various game models are defined in Table 1.

\section{Collusion in the Two-Echelon Supply Chain}

In this section, we study collusion in the two-echelon supply chain with one supplier and one retailer. Following Loch and $\mathrm{Wu}$ [38], we suppose that the market demand is a simple linear demand function, assuming that $q=d-p_{1}-p_{2}$, where $p_{1}$ and $p_{2}$ are the marginal revenue (price) of supplier and retailer, respectively. The price game of the vertical twoechelon supply chain is a sequential game process, the supplier (first mover) firstly determines its marginal price $p_{1}$ (equivalent to the wholesale price minus the cost $w-c$ ), and then the retailer (second mover) decides its marginal price $p_{2}$ (equivalent to the retail price minus the wholesale price $p-w)$. Then, the two marginal prices jointly determine the final market price of the product $p=p_{1}+p_{2}$ (for ease of calculation, the product cost $c$ is ignored as 0 ). The profit of supplier or retailer is given as follows:

$$
\pi_{i}=p_{i} q=p_{i}\left(d-p_{1}-p_{2}\right)=p_{i}\left(d-\sum_{j=1}^{2} p_{j}\right), \quad i=1,2
$$

4.1. Collusion under Sequential Game. According to collusion theory (CT), we first analyze collusion between supplier and retailer in the two-echelon supply chain under the sequential game. The sequential game is similar to Stackelberg game in which the supplier and retailer quote in turn.

4.1.1. Sequential Stackelberg Model. When the supplier and retailer play sequential game, the solution of reverse selection is as follows.

First, the maximization profit of the retailer is

$$
\begin{aligned}
& \pi_{s 2}^{\text {Seq }}=\max _{p_{2}} \pi_{2}\left(p_{1}, p_{2}\right), \\
& \text { s.t. } p_{i} \geq 0, \quad 5 i=1,2 .
\end{aligned}
$$

Therefore, the optimal reaction curve of retailer to supplier's price quotation is

$$
\begin{gathered}
\frac{d \pi_{2}\left(p_{1}, p_{2}\right)}{d p_{2}}=d-p_{1}-2 p_{2}=0, \\
p_{2}\left(p_{1}\right)=\frac{1}{2}\left(d-p_{1}\right) .
\end{gathered}
$$

Substituting the above reaction curve $p_{2}\left(p_{1}\right)$ into the supplier decision function to solve the optimal price quotation, we have

$$
\begin{aligned}
\pi_{s 1}^{\mathrm{Seq}} & =\max _{p_{1}} \pi_{1}\left(p_{1}, p_{2}\left(p_{1}\right)\right), \\
\text { s.t. } p_{i} \geq 0, \quad i=1,2, & \\
\frac{d \pi_{1}\left(p_{1}, p_{2}\left(p_{1}\right)\right)}{d p_{1}} & =\frac{1}{2} d-p_{1}=0 .
\end{aligned}
$$

Then, we obtain the optimal marginal price of the supplier $p_{s 1}^{\text {Seq* }}=(1 / 2) d$ and the retailer $p_{s 2}^{\text {Seq* }}=(1 / 4) d$, the optimal demand $q_{s}^{\mathrm{Seq} *}=(1 / 4) d$, and the maximum profit of the supplier $\pi_{s 1}^{\text {Seq* }}=(1 / 8) d^{2}$ and retailer $\pi_{s 2}^{\text {Seq* }}=(1 / 16) d^{2}$.

4.1.2. Sequential Collusion Model. According to CT, when the supplier and retailer collude price to maximize profits, their decision objective of collusion becomes

$$
\begin{aligned}
\pi_{m i}^{\mathrm{Seq}} & =\max _{p_{1}, p_{2}} \frac{1}{2} \llbracket \pi_{1}\left(p_{1}, p_{2}\right)+\pi_{2}\left(p_{1}, p_{2}\right) \rrbracket, \\
\text { s.t. } p_{i} & \geq 0, \quad i=1,2 .
\end{aligned}
$$

This analysis model is similar to microeconomics [2], assuming that supplier and retailer equally allocate all profits come from collusion. This paper also gives a more comprehensive analysis in Section 7, considering the random profit sharing of price collusion. 


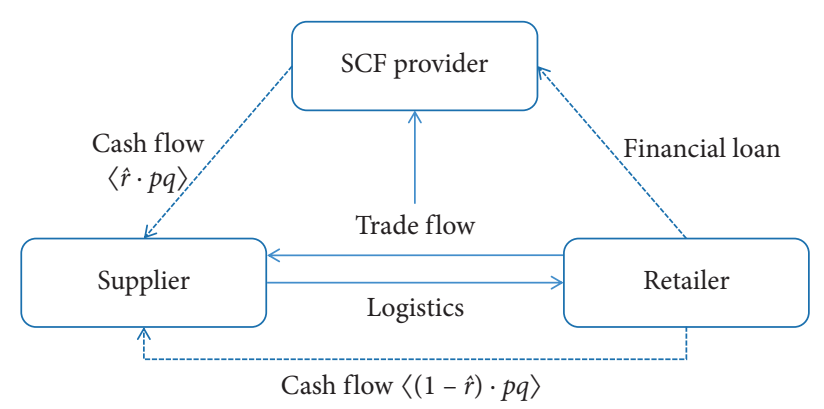

FIgURE 1: SCF transaction structure of the two-echelon supply chain.

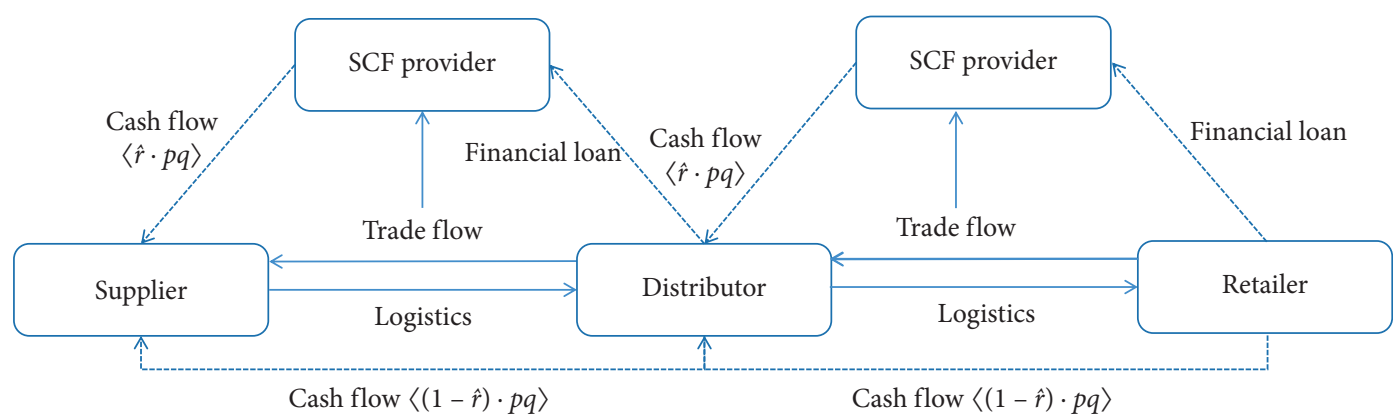

FIGURE 2: SCF transaction structure of the three-echelon supply chain.

$\frac{\partial(1 / 2) \llbracket \pi_{1}\left(p_{1}, p_{2}\right)+\pi_{2}\left(p_{1}, p_{2}\right) \rrbracket}{\partial p_{i}}=\frac{1}{2} d-\left(p_{1}+p_{2}\right)=0, \quad i=1,2$.

Through the above solution, we have the optimal marginal price of the supplier $p_{m 1}^{\text {Seq* }}=(1 / 4) d$ and the retailer $p_{m 2}^{\text {Seq* }}=(1 / 4) d$ under the price collusion, the optimal demand $q_{m}^{\text {Seq }}=(1 / 2) d$, and the maximum profit of the supplier and retailer $\pi_{m 1}^{\text {Seq* }}=(1 / 8) d^{2}$ and $\pi_{m 2}^{\text {Seq* }}=(1 / 8) d^{2}$.

4.1.3. Sequential Cheat Model. In the sequential game, the supplier has the first-mover advantage over the retailer. However, this advantage becomes a disadvantage in collusion. When the supplier and retailer quote price one after another, the retailer is most likely to cheat in price collusion to maximize its profits at a given supplier price, thus damaging the profits of supplier. We analyze the cheat behavior in collusion as follows.

According to the collusion agreement, the supplier first quotes $p_{d 1}^{\text {Seq* }}=(1 / 4) d$ based on the goal of maximizing the profit of collusion. However, owing to the inferiority of the first mover, the retailer may produce cheat behavior to maximize its own profits. Therefore, the decision function of the retailer will become the following form:

$$
\begin{aligned}
& \pi_{d 2}^{\mathrm{Seq}}=\max _{p_{2}} \pi_{2}\left(p_{d 1}^{\mathrm{Seq} *}, p_{2}\right), \\
& \text { s.t. } p_{i} \geq 0, \quad i=2 .
\end{aligned}
$$

Then, we solve the following:

$$
\frac{d \pi_{2}\left(p_{d 1}^{\mathrm{Seq} *}, p_{2}\right)}{d p_{2}}=\frac{3}{4} d-2 p_{2}=0
$$

We get the optimal marginal price of retailer when cheat behavior in collusion $p_{d 2}^{\text {Seq* }}=(3 / 8) d$, the demand $q_{d}^{\text {Seq * }}=(3 / 8) d$, and the maximized profit of supplier $\pi_{d 1}^{\text {Seq* }}=$ $(3 / 32) d^{2}$ and retailer $\pi_{d 2}^{\text {Seq* }}=(9 / 64) d^{2}$. That is, for a singleperiod game, the profit of cheat behavior is higher than the profit of collusion for retailer, and there is economic temptation of cheat behavior. The profit of retailer for cheat behavior is $\pi_{d 2}^{\text {Seq* }}=(9 / 64) d^{2}$.

4.1.4. Boundary Condition of Sequential Game. Once producing cheat behavior, the retailer and supplier will stop collusion and resume market price cooperation. Therefore, we compare the profits of collusion and the profits of cheat behavior and maker cooperation for the retailer to determine the boundary conditions of price collusion. At this point, according to CT in microeconomics [2], the decisionmaking process of the regulatory measures for the cheat behavior in collusion is as follows:

$$
\begin{aligned}
& \pi_{m 2}^{\text {Seq* }}+\delta \pi_{m 2}^{\text {Seq* }}+\delta^{2} \pi_{m 2}^{\text {Seq* }}+\delta^{3} \pi_{m 2}^{\text {Seq* }}+\cdots+\delta^{n} \pi_{m 2}^{\text {Seq* }}+\cdots \\
> & \pi_{d 2}^{\text {Seq* }}+\delta \pi_{s 2}^{\text {Seq* }}+\delta^{2} \pi_{s 2}^{\text {Seq* }}+\delta^{3} \pi_{s 2}^{\text {Seq* }}+\cdots+\delta^{n} \pi_{s 2}^{\text {Seq* }}+\cdots
\end{aligned}
$$


TABle 1: Notation and description.

\begin{tabular}{|c|c|}
\hline Notation & Description \\
\hline$i$ & $\begin{array}{c}\text { In the two-echelon supply chain, } i=1,2 \text { is supplier and retailer. In the three-echelon supply chain, } i=1,2,3 \text { is supplier, } \\
\text { distributor, and retailer }\end{array}$ \\
\hline$p_{i}$ & The marginal price (revenue) of $i$ \\
\hline$d$ & Potential demand of the market \\
\hline$q$ & The actual demand of the market \\
\hline$\pi_{i}$ & The profits of $i$ \\
\hline \multicolumn{2}{|r|}{ In the two-echelon supply chain with supplier and retailer } \\
\hline$p_{s i}^{\text {Seq }}$ & The marginal price (revenue) of $i$ under sequential Stackelberg model \\
\hline$q_{s}^{\text {Seq }}$ & The actual demand of the market under sequential Stackelberg model \\
\hline$\pi_{s i}^{\text {Seq }}$ & The profits of $i$ under sequential Stackelberg model \\
\hline$p_{m i}^{\text {Seq }}$ & The marginal price (revenue) of $i$ under sequential collusion model \\
\hline$q_{m}^{\mathrm{Seq}}$ & The actual demand of the market under sequential collusion model \\
\hline$\pi_{m i}^{\text {Seq }}$ & The profits of $i$ under sequential collusion model \\
\hline$p_{d i}^{\text {seq }}$ & The marginal price (revenue) of $i$ under sequential cheat model \\
\hline$q_{d}^{\text {sil }}$ & The actual demand of the market under sequential cheat model \\
\hline$\pi_{d i}^{\mathrm{Seq}}$ & The profits of $i$ under sequential cheat model \\
\hline$p_{c i}^{\text {Sim }}$ & The marginal price (revenue) of $i$ under simultaneous Cournot model \\
\hline$q_{c}^{\text {Sim }}$ & The actual demand of the market under simultaneous Cournot model \\
\hline$\pi_{c i}^{\mathrm{Sim}}$ & The profits of $i$ under simultaneous Cournot model \\
\hline$p_{m i}^{\mathrm{Sim}}$ & The marginal price (revenue) of $i$ under simultaneous collusion model \\
\hline$q_{m}^{\mathrm{Sim}}$ & The actual demand of the market under simultaneous collusion model \\
\hline$\pi_{m i}^{\mathrm{Sim}}$ & The profits of $i$ under simultaneous collusion model \\
\hline$p_{d i}^{\text {Sim }}$ & The marginal price (revenue) of $i$ under simultaneous cheat model \\
\hline$q_{d}^{\text {Sim }}$ & The actual demand of the market under simultaneous cheat model \\
\hline$\pi_{d i}^{\mathrm{Sim}}$ & The profits of $i$ under simultaneous cheat model \\
\hline
\end{tabular}

In the three-echelon supply chain with supplier, distributor, and retailer

\begin{tabular}{|c|c|}
\hline$p_{s i}$ & The marginal price (revenue) of $i$ under Benchmark_Stackelberg $n$ \\
\hline$q_{s}$ & The actual demand of the market under Benchmark_Stackelberg $\mathrm{n}$ \\
\hline$\pi_{s i}$ & The profits of $i$ under Benchmark_Stackelberg model \\
\hline$p_{m i}^{\mathrm{s} D}$ & The marginal price (revenue) of $i$ under S_D_Collusion mode \\
\hline$q_{m}^{S D}$ & The actual demand of the market under S_D_Collusion mode \\
\hline$\pi_{m i}^{\mathrm{SD}}$ & The profits of $i$ under S_D_Collusion model \\
\hline$p_{d i}^{\mathrm{SD}}$ & The marginal price (revenue) of $i$ under S_D_Cheat model \\
\hline$q_{d}^{\mathrm{SD}}$ & The actual demand of the market under S_D_Cheat model \\
\hline$\pi_{d i}^{\mathrm{SD}}$ & The profits of $i$ under S_D_Cheat model \\
\hline$p_{m i}^{D R}$ & The marginal price (revenue) of $i$ under D_R_Collusion mode \\
\hline$q_{m}^{\mathrm{DR}}$ & The actual demand of the market under D_R_Collusion mode \\
\hline$\pi_{m i}^{\mathrm{DR}}$ & The profits of $i$ under D_R_Collusion model \\
\hline$p_{d i}^{\mathrm{DR}}$ & The marginal price (revenue) of $i$ under D_R_Cheat model \\
\hline$q_{d}^{\mathrm{DR}}$ & The actual demand of the market under D_R_Cheat model \\
\hline$\pi_{d i}^{\mathrm{DR}}$ & The profits of $i$ under D_R_Cheat model \\
\hline$p_{m i}^{\mathrm{SR}}$ & The marginal price (revenue) of $i$ under S_R_Collusion mode \\
\hline$q_{m}^{\mathrm{SR}}$ & The actual demand of the market under S_R_Collusion mode \\
\hline$\pi_{m i}^{\mathrm{SR}}$ & The profits of $i$ under S_R_Collusion model \\
\hline$p_{d i}^{\mathrm{SR}}$ & The marginal price (revenue) of $i$ under S_R_Cheat model \\
\hline$q_{d}^{\mathrm{SR}}$ & The actual demand of the market under S_R_Cheat model \\
\hline$\pi_{d i}^{\mathrm{SR}}$ & The profits of $i$ under S_R_Cheat model \\
\hline$\pi_{\text {Simi }}$ & The profits of $i$ under the simultaneous game \\
\hline$\delta_{\text {Seq }}^{*}$ & The critical discount factor under the sequential game \\
\hline$\delta_{\mathrm{Sim}}^{*}$ & The critical discount factor under the simultaneous game \\
\hline$\delta_{2}^{5 \mathrm{D} *}$ & The critical discount factor under the S_D_Collusion game \\
\hline$\delta_{3}^{\mathrm{DR} *}$ & The critical discount factor under the D_R_Collusion game \\
\hline$\delta_{3}^{\xi R *}$ & The critical discount factor under the S_R_Collusion game \\
\hline$\left(\gamma_{1}, \gamma_{2}\right)$ & Profit sharing factor between the supplier and retailer \\
\hline$\left(\varepsilon_{1}, \varepsilon_{2}\right)$ & The probability of cheating of the supplier and retailer \\
\hline & Probability of collusion \\
\hline
\end{tabular}

* In the two-echelon supply chain, sequential Stackelberg model represents the benchmark model under the sequential game, sequential collusion model represents the collusion model under the sequential game, sequential cheat model represents the cheat model under the sequential game, simultaneous Cournot model represents the benchmark model under the simultaneous game, simultaneous collusion model represents the collusion model under the simultaneous game, and simultaneous cheat model represents the cheat model under the simultaneous game. In the three-echelon supply chain, Benchmark_Stackelberg model represents the benchmark model (i.e., Stackelberg game), S_D_Collusion model represents the collusion model between the supplier and distributor, S_D_Cheat model represents the cheat model between the supplier and distributor, D_R_Collusion model represents the collusion model between the distributor and retailer, D_R_Cheat model represents the cheat model between the distributor and retailer, S_R_Collusion model represents the collusion model between the supplier and retailer, and S_R_Cheat model represents the cheat model between the supplier and retailer. 
where $\delta \in[0,1]$ refers the discount factor of the profit.

$$
\begin{aligned}
\pi_{m 2}^{\text {Seq* }} \lim _{n \longrightarrow \infty} \frac{\left(1-\delta^{n}\right)}{1-\delta}>\pi_{d 2}^{\text {Seq* }}+\pi_{s 2}^{\text {Seq* }} \lim _{n \longrightarrow \infty} \frac{\delta\left(1-\delta^{n}\right)}{1-\delta}, \\
\frac{\pi_{m 2}^{\text {Seq* }}}{1-\delta}>\pi_{d 2}^{\text {Seq* }}+\frac{\delta \pi_{s 2}^{\text {Seq* }}}{1-\delta} \\
\pi_{m 2}^{\text {Seq* }}>(1-\delta) \pi_{d 2}^{\text {Seq* }}+\delta \pi_{s 2}^{\text {Seq* }}
\end{aligned}
$$

Seeing that $\pi_{d 2}^{\text {Seq* }}>\pi_{m 2}^{\text {Seq* }}>\pi_{s 2}^{\text {Seq* }}$, then

$$
\delta \geq \delta_{\text {Seq }}^{*}=\frac{\pi_{d 2}^{\text {Seq* }}-\pi_{m 2}^{\text {Seq* }}}{\pi_{d 2}^{\text {Seq* }}-\pi_{s 2}^{\text {Seq* }}}=\frac{(9 / 64) d^{2}-(8 / 64) d^{2}}{(9 / 64) d^{2}-(4 / 64) d^{2}}=\frac{1}{5}>0 .
$$

According to the hypothesis of punishment strategy, when the discount factor satisfies the above conditions, the collusion is stable and cannot be disintegrated.

Proposition 1. In a two-echelon supply chain under the sequential game, the profits of retailer in collusion, cheating, and sequential game satisfy $\pi_{d 2}^{\text {Seq* }}=(9 / 64) d^{2}$ $>\pi_{m 2}^{\text {Seq* }}=(8 / 64) d^{2}>\pi_{s 2}^{\text {Seq* }}=(4 / 64) d^{2}$.

(1) When the discount factor satisfies $\delta \geq \delta_{\text {Seq }}^{*}=(1 / 5)$, the supplier and retailer are likely to collude to get higher loans from the SCF service provider in the two-echelon trade-based SCF transaction structure.

(2) When the discount factor satisfies $\delta<\delta_{\text {Seq }}^{*}=(1 / 5)$, the two-echelon trade-based SCF transaction structure has the ability to actively restrain price collusion, that is, self-restraint, which can effectively avoid the price collusion behavior.

Proof. It follows directly from the above analysis and is thus omitted.

4.2. Collusion under Simultaneous Game. The simultaneous game is similar to Cournot game in which the supplier and retailer quote at the same time.

4.2.1. Simultaneous Cournot Model. When the supplier and retailer play simultaneous game, they first consider the reaction curve of each other to their own pricing decision and then make the optimal pricing decision in the way of reverse selection. After repeated games, the equilibrium strategy of the simultaneous game will be fixed at the intersection of the response curve of supplier and retailer to each other's pricing decision. First, the profit maximization of the supplier and retailer respectively is as follows:

$$
\begin{aligned}
& \left\{\begin{array}{l}
\pi_{c 1}^{\mathrm{Sim}}=\max _{p_{1}} \pi_{1}\left(p_{1}, p_{2}\right), \\
\pi_{c 2}^{\mathrm{Sim}}=\max _{p_{2}} \pi_{2}\left(p_{1}, p_{2}\right),
\end{array}\right. \\
& \text { s.t. } p_{i} \geq 0, \quad i=1,2 .
\end{aligned}
$$

Therefore, under the simultaneous game, the optimal reaction curves of the supplier to retailer's quoted price and the retailer to supplier's quoted price are as follows:

$$
\begin{aligned}
& \left\{\begin{array}{l}
\frac{d \pi_{1}\left(p_{1}, p_{2}\right)}{d p_{1}}=d-2 p_{1}-p_{2}=0 \\
\frac{d \pi_{2}\left(p_{1}, p_{2}\right)}{d p_{2}}=d-p_{1}-2 p_{2}=0
\end{array}\right. \\
& \left\{\begin{array}{l}
p_{c 1}^{\operatorname{Sim}}\left(p_{c 2}^{\operatorname{Sim}}\right)=\frac{1}{2}\left(d-p_{c 2}^{\operatorname{Sim}}\right) \\
p_{c 2}^{\operatorname{Sim}}\left(p_{c 1}^{\text {Sim }}\right)=\frac{1}{2}\left(d-p_{c 1}^{\text {Sim }}\right) .
\end{array}\right.
\end{aligned}
$$

Based on the homologous structures of the above two reaction functions, the optimal pricing for the simultaneous game equilibrium can be easily found by substituting the first reaction curve into the second one. Then, we get the optimal marginal price of the supplier $p_{c 1}^{\operatorname{Sim} *}=(1 / 3) d$ and the retailer $p_{c 2}^{\operatorname{Sim} *}=(1 / 3) d$, the optimal demand $q_{c}^{\operatorname{Sim} *}=(1 / 3) d$, and the maximum profit of the supplier and retailer $\pi_{c 1}^{\operatorname{Sim} *}=(1 / 9) d^{2}$ and $\pi_{c 2}^{\text {Sim } *}=(1 / 9) d^{2}$.

4.2.2. Simultaneous Collusion Model. According to CT, when the supplier and retailer collude price to maximize profits, their price collusion decision objectives are as follows:

$$
\begin{array}{r}
\pi_{m i}^{\mathrm{Sim}}=\max _{p_{1}, p_{2}} \frac{1}{2} \llbracket \pi_{1}\left(p_{1}, p_{2}\right)+\pi_{2}\left(p_{1}, p_{2}\right) \rrbracket, \\
\text { s.t. } p_{i} \geq 0, \quad i=1,2 .
\end{array}
$$

This analysis method is similar to microeconomics, assuming that supplier and retailer equally distribute all profits of price collusion.

$$
\frac{\partial(1 / 2) \llbracket \pi_{1}\left(p_{1}, p_{2}\right)+\pi_{2}\left(p_{1}, p_{2}\right) \rrbracket}{\partial p_{i}}=\frac{1}{2} d-\left(p_{1}+p_{2}\right)=0, \quad i=1,2 .
$$

Through the above solution, we have the optimal marginal price of the supplier $p_{m 1}^{S i m *}=(1 / 4) d$ and the retailer $p_{m 2}^{\text {Sim* }}=(1 / 4) d$ under the price collusion, the optimal demand $q_{m}^{\operatorname{Sim} *}=(1 / 2) d$, and the maximum profit of the supplier and retailer $\pi_{m 1}^{\operatorname{Sim} *}=(1 / 8) d^{2}$ and $\pi_{m 2}^{\operatorname{Sim} *}=(1 / 8) d^{2}$.

4.2.3. Simultaneous Cheat Model. Based on the analysis of the optimal pricing decision under the price collusion and simultaneous games, the possible cheat behaviors of the supplier and retailer are analyzed. As the leader of two-level supply chain, the original advantages of supplier become disadvantages when cheat occurs under the sequential game. Under the premise of the sequential game, it is almost impossible for the supplier to cheat because its cheating behavior can be discovered by the retailer in "one time" game, but the cheat behavior of the retailer can be found at 
least twice in the game process. Then, supplier thinks the retailer may be cheating. When the hypothesis becomes a simultaneous game, the supplier and retailer may cheat because there is no sequential relationship between their pricing behaviors. Next, we analyze the cheat behaviors of the supplier and retailer.

According to the collusion agreement, the supplier first quotes $p_{d 1}^{\text {Sim* }}=(1 / 4) d$ on the basis of the decision of maximizing the profit of price collusion. However, the supplier realizes that the retailer may take cheating to damage his own interests. After the supplier completes his own pricing, the decision making of the retailer's cheat behavior is based on the new profit function to decide its new quotation $p_{2}$.

$$
\begin{aligned}
& \pi_{d 2}^{\mathrm{Sim}}=\max _{p_{2}} \pi_{2}\left(p_{d 1}^{\operatorname{Sim} *}, p_{2}\right), \\
& \text { s.t. } p_{i} \geq 0, \quad i=2 .
\end{aligned}
$$

Then, we solve the following:

$$
\frac{d \pi_{2}\left(p_{d 1}^{\operatorname{Sim} *}, p_{2}\right)}{d p_{2}}=\frac{3}{4} d-2 p_{2}=0 .
$$

We have the optimal marginal price of retailer when cheating in price collusion $p_{d 2}^{\text {Sim* }}=(3 / 8) d$, the demand $q_{d}^{\operatorname{Sim} *}=(3 / 8) d$, and the maximum profit $\pi_{d 1}^{\operatorname{Sim} *}=(3 / 32) d^{2}$ and $\pi_{d 2}^{\text {Sim* }}=(9 / 64) d^{2}$. The profit of cheating for retailer is higher than the profit of price collusion for the single-period game, and there is the economic temptation of cheat. The cheat profit of retailer is $\pi_{d 2}^{\operatorname{Sim} *}=(9 / 64) d^{2}$.

4.2.4. Boundary Condition of Simultaneous Game. According to CT, the idea of preventing price collusion parties from cheat is to make the present value of price collusion profits higher than the present value of cheat and simultaneous game profits. Both the supplier and retailer are likely to cheat under the simultaneous game, so taking the larger critical discount factor as the constraint condition is necessary to regulate the occurrence of cheat in price collusion.

The "threat" of punishment at this time is that if the supplier or the retailer cheats in the price collusion, they will enter the simultaneous game forever, $\operatorname{so} \delta_{\text {Sim_2 }}^{*}=$ $\left(\pi_{d 2}^{\operatorname{Sim} *}-\pi_{m 2}^{\operatorname{Sim} *} / \pi_{d 2}^{\operatorname{Sim} *}-\pi_{c 2}^{\operatorname{Sim} *}\right)$, which shows that

$$
\delta_{S i m \_2}^{*}=\frac{\pi_{d 2}^{\operatorname{Sim} *}-\pi_{m 2}^{\operatorname{Sim} *}}{\pi_{d 2}^{\operatorname{Sim} *}-\pi_{c 2}^{\operatorname{Sim} *}}=\frac{(9 / 64) d^{2}-(8 / 64) d^{2}}{(9 / 64) d^{2}-(1 / 9) d^{2}}=\frac{9}{17} .
$$

Because the supplier and retailer are homogeneous in the simultaneous game, the following is easy to know:

$$
\delta_{\text {Sim_1 }}^{*}=\delta_{\text {Sim_2 }}^{*} .
$$

Therefore, $\delta \geq \delta_{\text {Sim }}^{*}=\max \left\{\delta_{\text {Sim_1 }_{1}}^{*}, \delta_{\text {Sim }_{2}}^{*}\right\}=(9 / 17)$, and the critical discount factor in the simultaneous game is $\delta_{\text {Sim }}^{*}=(9 / 17)$.

Proposition 2. In a two-echelon supply chain under the simultaneous game, the profits of retailer in price collusion, cheating, and simultaneous game satisfy $\pi_{d 2}^{\text {Sim* }}=(9 / 64) d^{2}$ $>\pi_{m 2}^{\text {Sim* }}=(8 / 64) d^{2}>\pi_{c 2}^{\text {Sim* }}=(1 / 9) d^{2}$.

(1) When the discount factor satisfies $\delta \geq \delta_{\text {Sim }}^{*}=(9 / 17)$, the supplier and retailer are likely to collude price to get higher loans from the SCF service provider in the two-echelon trade-based SCF transaction structure.

(2) When the discount factor satisfies $\delta<\delta_{\text {Sim }}^{*}=(9 / 17)$, the two-echelon trade-based SCF transaction structure has the ability to actively restrain price collusion, that is, self-restraint, which can effectively avoid the price collusion behavior.

Proof. It follows directly from the above analysis and is thus omitted.

\section{Price Collusion in the Three-Echelon Supply Chain}

Considering that the three-echelon supply chain is composed of one supplier, one distributor, and one retailer, the increase of supply chain levels leads to different forms of price collusion. This section focuses on the following different forms of price collusion under complete information:

(1) Price collusion between the supplier and distributor (see Figure 3(a))

(2) Price collusion between the distributor and retailer (see Figure 3(b))

(3) Price collusion between the supplier and retailer (see Figure 3(c))

The market demand assumption in this section also refers to Loch and $\mathrm{Wu}$ [38]. Therefore, the general linear demand can be expressed as

$$
q\left(p_{1}, p_{2}, p_{3}\right)=d-p_{1}-p_{2}-p_{3}=d-\sum_{i=1}^{3} p_{i}
$$

The profit function of each member in the three-echelon supply chain can be expressed as follows:

$$
\pi_{i}\left(p_{1}, p_{2}, p_{3}\right)=p_{i} q\left(p_{1}, p_{2}, p_{3}\right)=p_{i}\left(d-\sum_{i=1}^{3} p_{i}\right), \quad i=1,2,3 .
$$

5.1. Price Collusion under Sequential Game. According to $\mathrm{CT}$, we first analyze price collusion with or without cheat behavior of the supplier, distributor, and retailer in the three-echelon supply chain under the sequential game. The sequential game is similar to Stackelberg game in which the supplier, distributor, and retailer quote in turn.

5.1.1. Benchmark Model: Stackelberg Game. Stackelberg game is a benchmark model for the supplier, distributor, and retailer to quote in turn. According to $\mathrm{CT}$, we first analyze the Stackelberg game in the three-echelon supply chain and 


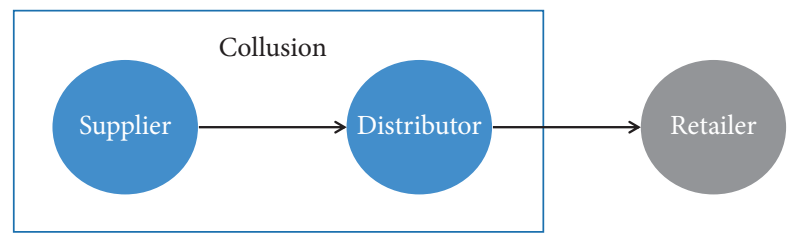

(a)

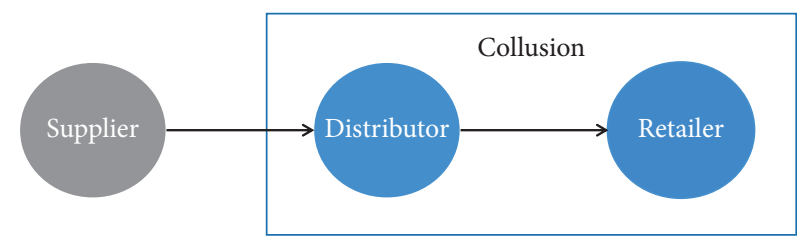

(b)

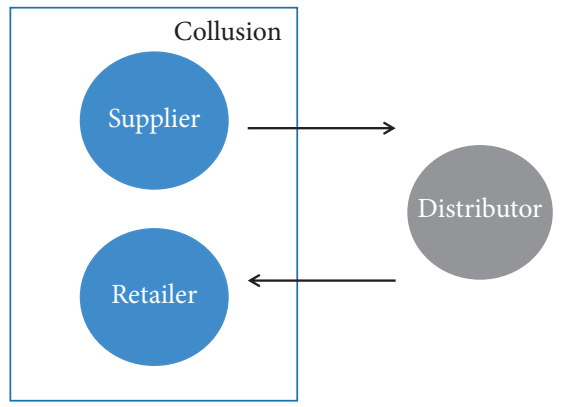

(c)

Figure 3: (a) Collusion between the supplier and distributor. (b) Collusion between the distributor and retailer. (c) Collusion between the supplier and retailer.

then the price collusion and cheating in three different forms of price collusion. When the supplier, distributor, and retailer play Stackelberg game, the solution of reverse selection is as follows. First, the profit maximization of the retailer is

$$
\begin{aligned}
& \pi_{\mathrm{Seq} 3}=\max _{p_{3}} \pi_{3}\left(p_{1}, p_{2}, p_{3}\right), \\
& \text { s.t. } p_{i} \geq 0, \quad i=1,2,3 .
\end{aligned}
$$

Therefore, the optimal reaction curve of retailer to the supplier's and distributor's quotations is as follows:

$$
\begin{gathered}
\frac{d \pi_{3}\left(p_{1}, p_{2}, p_{3}\right)}{d p_{3}}=d-p_{1}-p_{2}-2 p_{3}=0, \\
p_{3}\left(p_{1}, p_{2}\right)=\frac{1}{2}\left(d-p_{1}-p_{2}\right) .
\end{gathered}
$$

Substituting the above reaction curve $p_{3}\left(p_{1}, p_{2}\right)$ into the decision function of the distributor to solve the optimal quoted price, we have

$$
\begin{aligned}
& \pi_{\mathrm{Seq} 2}=\max _{p_{2}} \pi_{2}\left(p_{1}, p_{2}, p_{3}\left(p_{1}, p_{2}\right)\right), \\
& \text { s.t. } p_{i} \geq 0, \quad i=1,2 .
\end{aligned}
$$

Then, the optimal reaction curve of the distributor to the supplier's quotation is

$$
\begin{aligned}
\frac{d \pi_{2}\left(p_{1}, p_{2}, p_{3}\left(p_{1}, p_{2}\right)\right)}{d p_{2}} & =\frac{1}{2}\left(d-p_{1}\right)-p_{2}=0, \\
p_{2}\left(p_{1}\right) & =\frac{1}{2}\left(d-p_{1}\right) .
\end{aligned}
$$

Substituting the above reaction curve $p_{2}\left(p_{1}\right)$ into the decision function of the supplier to solve the optimal quoted price, we get

$$
\begin{aligned}
\pi_{\mathrm{Seq} 1} & =\max _{p_{1}} \pi_{1}\left(p_{1}, p_{2}\left(p_{1}\right)\right), \\
\text { s.t. } p_{i} \geq 0, \quad i=1 & \\
\frac{d \pi_{1}\left(p_{1}, p_{2}\left(p_{1}\right)\right)}{d p_{1}} & =\frac{1}{4} d-\frac{1}{2} p_{1}=0
\end{aligned}
$$

At last, we obtain the optimal marginal price of the supplier $p_{s 1}^{*}=(1 / 2) d$, the distributor $p_{s 2}^{*}=(1 / 4) d$, and the retailer $p_{s 3}^{*}=(1 / 8) d$, the optimal demand $q_{s}^{*}=(1 / 8) d$, and the maximum profit of the supplier, the distributor, and the retailer

$\pi_{\text {Seq1 }}^{*}=(1 / 16) d^{2}, \pi_{\text {Seq2 }}^{*}=(1 / 32) d^{2}$, and $\pi_{\text {Seq } 3}^{*}=(1 / 64) d^{2}$.

5.1.2. Price Collusion between the Supplier and Distributor. (1) S_D_Collusion Model. According to CT, when the supplier and distributor collude price in order to maximize profits, the decision objectives of collusion will be

$$
\begin{aligned}
\pi_{m i}^{\mathrm{SD}} & =\max _{p_{1}, p_{2}} \frac{1}{2} \llbracket \pi_{1}\left(p_{1}, p_{2}, p_{3}\left(p_{1}, p_{2}\right)\right)+\pi_{2}\left(p_{1}, p_{2}, p_{3}\left(p_{1}, p_{2}\right)\right) \rrbracket, \\
\text { s.t. } p_{i} & \geq 0, \quad i=1,2 .
\end{aligned}
$$

However, to solve the problem of profit maximization, the first step is to determine the optimal price reaction curve of the retailer to the price quotation of the supplier and the distributor based on the reverse selection strategy. We can know that the profit maximization of the retailer is

$$
\begin{aligned}
& \pi_{m 3}^{\mathrm{SD}}=\max _{p_{3}} \pi_{3}\left(p_{1}, p_{2}, p_{3}\right), \\
& \text { s.t. } p_{i} \geq 0, \quad i=1,2,3 .
\end{aligned}
$$


We easily get this optimal reaction curve as follows:

$$
\begin{gathered}
\frac{d \pi_{3}\left(p_{1}, p_{2}, p_{3}\right)}{d p_{3}}=d-p_{1}-p_{2}-2 p_{3}=0, \\
p_{3}\left(p_{1}, p_{2}\right)=\frac{1}{2}\left(d-p_{1}-p_{2}\right) .
\end{gathered}
$$

Substituting the above reaction curve $p_{3}\left(p_{1}, p_{2}\right)$ into the decision function of price collusion, we can solve the optimal quoted price as follows:

$$
\frac{\partial(1 / 2) \llbracket \pi_{1}\left(p_{1}, p_{2}, p_{3}\left(p_{1}, p_{2}\right)\right)+\pi_{2}\left(p_{1}, p_{2}, p_{3}\left(p_{1}, p_{2}\right)\right) \rrbracket}{\partial p_{i}}=\frac{1}{4} d-\frac{2}{4}\left(p_{1}+p_{2}\right)=0
$$

At last, we obtain the optimal marginal price of the supplier $p_{m 1}^{\mathrm{SD} *}=(1 / 4) d$, the distributor $p_{m 2}^{\mathrm{SD} *}=(1 / 4) d$, and the retailer $p_{m 3}^{\mathrm{SD} *}=(1 / 4) d$, the optimal demand $q_{m}^{S D *}=(1 / 4) d$, and the maximum profit of the supplier, the distributor, and the retailer $\pi_{m 1}^{S D *}=(1 / 16) d^{2}, \pi_{m 2}^{S D *}=(1 / 16) d^{2}$, and $\pi_{m 3}^{S D *}=(1 / 16) d^{2}$.

(2) S_D_Cheat Model. This model is similar to the previous analysis of the cheating model because the firstmover advantage of the supplier becomes a disadvantage. The distributor is most likely to cheat in the price collusion, thus damaging the profit of supplier. The profit maximization and reaction curve of retailer are as follows:

$$
\begin{aligned}
\pi_{d 3}^{\mathrm{SD}} & =\max _{p_{3}} \pi_{3}\left(p_{1}, p_{2}, p_{3}\right), \\
\text { s.t. } p_{i} \geq 0, \quad i=1,2,3, & \\
p_{3}\left(p_{1}, p_{2}\right) & =\frac{1}{2}\left(d-p_{1}-p_{2}\right) .
\end{aligned}
$$

According to the price collusion agreement, the supplier shall first quote $p_{d 1}^{S D *}=(1 / 4) d$ on the basis of the decision of maximizing the profit of price collusion. After the supplier completes his own pricing, the decision making of distributor's cheating behavior is to decide his new quotation $p_{2}$ based on the new profit function.

$$
\begin{aligned}
& \quad \pi_{d 2}^{\mathrm{SD}}=\max _{p_{2}} \pi_{2}\left(p_{d 1}^{S D *}, p_{2}, p_{3}\left(p_{d 1}^{S D *}, p_{2}\right)\right), \\
& \text { s.t. } p_{i} \geq 0, \quad i=2 .
\end{aligned}
$$

Through the above objective function, we can have the entire optimal marginal price $p_{d 1}^{S D *}=$ $(1 / 4) d, p_{d 2}^{S D *}=(3 / 8) d$, and $p_{d 3}^{S D *}=(3 / 16) d$, the optimal demand $q_{d}^{S D *}=(3 / 16) d$, and all the optimal profits $\pi_{d 1}^{S D *}=(3 / 64) d^{2}, \pi_{d 2}^{S D *}=(9 / 128) d^{2}$, and $\pi_{d 3}^{S D *}=(9 / 256) d^{2}$.

According to the punishment mechanism of CT in microeconomics, the critical discount factor can be solved as follows:

$$
\delta_{2}^{S D} \geq \delta_{2}^{S D *}=\frac{\pi_{d 2}^{S D *}-\pi_{m 2}^{S D *}}{\pi_{d 2}^{S D *}-\pi_{s 2}^{*}}=\frac{(9 / 128) d^{2}-(1 / 16) d^{2}}{(9 / 128) d^{2}-(1 / 32) d^{2}}=\frac{1}{5} .
$$

Proposition 3. In a three-echelon supply chain, the distributor's profits of distributor in price collusion, cheating, and Stackelberg game satisfy $\pi_{d 2}^{S D *}=(9 / 128) d^{2}$ $>\pi_{m 2}^{S D *}=(1 / 16) d^{2}>\pi_{s 2}^{*}=(1 / 32) d^{2}$.

(1) When the discount factor satisfies $\delta_{2}^{S D} \geq \delta_{2}^{S D *}=(1 / 5)$, the supplier and distributor are likely to collude price to get higher loans from the SCF service provider in the three-echelon trade-based SCF transaction structure.

(2) When the discount factor satisfies $\delta_{2}^{S D} \geq \delta_{2}^{S D *}=(1 / 5)$, the three-echelon trade-based SCF transaction structure has the ability to actively restrain price collusion between the supplier and distributor, that is, self-restraint, which can effectively avoid the price collusion behavior.

Proof. It follows directly from the above analysis and is thus omitted.

5.1.3. Price Collusion between the Distributor and Retailer. (1) D_R_Collusion Model. According to CT, when the distributor and retailer collude price to maximize profits, their collusion decision objectives are

$$
\begin{aligned}
\pi_{m i}^{\mathrm{DR}} & =\max _{p_{2}, p_{3}} \frac{1}{2} \llbracket \pi_{2}\left(p_{1}, p_{2}, p_{3}\right)+\pi_{3}\left(p_{1}, p_{2}, p_{3}\right) \rrbracket, \\
\text { s.t. } p_{i} & \geq 0, \quad i=2,3 .
\end{aligned}
$$

By solving the following partial derivatives, we can get the optimal reaction curve of the distributor and retailer to the supplier' price quotation.

$$
\frac{\partial(1 / 2) \llbracket \pi_{2}\left(p_{1}, p_{2}, p_{3}\right)+\pi_{3}\left(p_{1}, p_{2}, p_{3}\right) \rrbracket}{\partial p_{i}}=\frac{1}{2}\left(d-p_{1}\right)-\left(p_{2}+p_{3}\right)=0 .
$$


The reaction curve is

$$
\begin{aligned}
p_{m 2}^{\mathrm{DR}} & =\frac{1}{4}\left(d-p_{1}\right), \\
p_{m 3}^{\mathrm{DR}} & =\frac{1}{4}\left(d-p_{1}\right), \\
p_{m 2}^{\mathrm{DR}}+p_{m 3}^{\mathrm{DR}} & =\frac{1}{2}\left(d-p_{1}\right) .
\end{aligned}
$$

Through the reverse selection strategy, we substitute the above reaction curve into the supplier's profit maximization, and the solution is as follows:

$$
\begin{gathered}
\pi_{m 1}^{\mathrm{DR}}=\max _{p_{1}} \pi_{1}\left(p_{1}, p_{m 2}^{\mathrm{DR}}\left(p_{1}\right), p_{m 3}^{\mathrm{DR}}\left(p_{1}\right)\right), \\
\text { s.t. } p_{i} \geq 0, \quad i=1, \\
\frac{d \pi_{1}\left(p_{1}, p_{m 2}^{\mathrm{DR}}\left(p_{1}\right), p_{m 3}^{\mathrm{DR}}\left(p_{1}\right)\right)}{d p_{1}}=\frac{1}{2} d-p_{1}=0 .
\end{gathered}
$$

At last, we obtain the optimal marginal price of the supplier $p_{m 1}^{D R *}=(1 / 2) d$, the distributor $p_{m 2}^{D R *}=(1 / 8) d$, and the retailer $p_{m 3}^{D R *}=(1 / 8) d$, the optimal demand $q_{m}^{D R *}=(1 / 4) d$, and the maximum profit $\pi_{m 1}^{D R *}=(1 / 8) d^{2}, \pi_{m 2}^{D R *}=(1 / 32) d^{2}$, and $\pi_{m 3}^{D R *}=(1 / 32) d^{2}$.

(2) D_R_Cheat Model. Similar to the analysis of the cheating behavior of the distributor under the price collusion between supplier and distributor, when they collude, the retailer obtains the motivation of cheating in the price collusion. At this time, the optimal marginal price of the supplier and distributor will be similar to that in the D_R_Collusion model, which is $p_{d 1}^{D R *}=(1 / 2) d$ and $p_{d 2}^{D R *}=(1 / 8) d$. Then, the decision making of retailer cheating behavior is based on the new profit function to determine its new quotation $p_{3}$ :

$$
\begin{aligned}
& \pi_{d 3}^{\mathrm{DR}}=\max _{p_{3}} \pi_{3}\left(p_{d 1}^{D R *}, p_{d 2}^{D R *}, p_{3}\right), \\
& \text { s.t. } p_{i} \geq 0, \quad i=3 .
\end{aligned}
$$

Through the above objective function, we get the retailer's optimal marginal price $p_{d 3}^{D R *}=(3 / 16) d$, the optimal demand $q_{d}^{D R *}=(3 / 16) d$, and all the optimal profits $\pi_{d 1}^{D R *}=$ $(3 / 32) d^{2}, \pi_{d 2}^{D R *}=(3 / 128) d^{2}$, and $\pi_{d 3}^{D R *}=(9 / 256) d^{2}$.

According to the punishment mechanism of CT in microeconomics, the critical discount factor can be solved as follows:

$$
\delta_{3}^{D R} \geq \delta_{3}^{D R *}=\frac{\pi_{d 3}^{D R *}-\pi_{m 3}^{D R *}}{\pi_{d 3}^{D R *}-\pi_{s 3}^{*}}=\frac{(9 / 256) d^{2}-(1 / 32) d^{2}}{(9 / 256) d^{2}-(1 / 64) d^{2}}=\frac{1}{5}
$$

Proposition 4. In a three-echelon supply chain, the profits of retailer in price collusion, cheating, and Stackelberg game satisfy

$\pi_{d 3}^{D R *}=(9 / 256) d^{2}>\pi_{m 3}^{D R *}=(1 / 32) d^{2}>\pi_{s 3}^{*}=(1 / 64) d^{2}$.

(1) When the discount factor satisfies $\delta_{3}^{D R} \geq \delta_{3}^{D R *}=(1 / 5)$, the distributor and retailer are likely to collude price to get higher loans from the SCF service provider in the three-echelon trade-based SCF transaction structure.

(2) When the discount factor satisfies $\delta_{3}^{D R}<\delta_{3}^{D R *}=(1 / 5)$, the three-echelon trade-based SCF transaction structure has the ability to actively restrain price collusion, that is, self-restraint, which can effectively avoid the price collusion behavior.

Proof. It follows directly from the above analysis and is thus omitted.

5.1.4. Price Collusion between the Supplier and Retailer. (1) $S \_R \_C o l l u s i o n$ Model. According to CT, when the supplier and retailer collude to maximize profits, their collusion decision objectives are

$$
\begin{aligned}
& \pi_{m i}^{\mathrm{SR}}=\max _{p_{1}, p_{3}} \frac{1}{2} \llbracket \pi_{1}\left(p_{1}, p_{2}, p_{3}\right)+\pi_{3}\left(p_{1}, p_{2}, p_{3}\right) \rrbracket, \\
& \text { s.t. } p_{i} \geq 0, \quad i=1,2,3 .
\end{aligned}
$$

By solving the following partial derivatives, we can get the optimal reaction curve of the supplier and retailer to the distributor's price quotation.

$$
\frac{\partial(1 / 2) \llbracket \pi_{1}\left(p_{1}, p_{2}, p_{3}\right)+\pi_{3}\left(p_{1}, p_{2}, p_{3}\right) \rrbracket}{\partial p_{i}}=\frac{1}{2}\left(d-p_{2}\right)-\left(p_{1}+p_{3}\right)=0 .
$$


The reaction curve is

$$
\begin{aligned}
p_{m 1}^{\mathrm{SR}} & =\frac{1}{4}\left(d-p_{2}\right), \\
p_{m 3}^{\mathrm{SR}} & =\frac{1}{4}\left(d-p_{2}\right), \\
p_{m 1}^{\mathrm{SR}}+p_{m 3}^{\mathrm{SR}} & =\frac{1}{2}\left(d-p_{2}\right) .
\end{aligned}
$$

Through the reverse selection strategy, the above reaction curve is put into the profit maximization of distributor, and the solution is as follows:

$$
\begin{aligned}
\pi_{m 2}^{\mathrm{SR}} & =\max _{p_{2}} \pi_{2}\left(p_{m 1}^{\mathrm{SR}}\left(p_{2}\right), p_{2}, p_{m 3}^{\mathrm{SR}}\left(p_{2}\right)\right), \\
\text { s.t. } p_{i} & \geq 0, \quad i=2, \\
\frac{d \pi_{2}\left(p_{m 1}^{\mathrm{SR}}\left(p_{2}\right), p_{2}, p_{m 3}^{\mathrm{SR}}\left(p_{2}\right)\right)}{d p_{2}} & =\frac{1}{2} d-p_{2}=0 .
\end{aligned}
$$

At last, we obtain the optimal marginal price of the supplier $p_{m 1}^{S R *}=(1 / 8) d$, the distributor $p_{m 2}^{S R *}=(1 / 2) d$, and the retailer $p_{m 3}^{S R *}=(1 / 8) d$, the optimal demand $q_{m}^{S R *}=(1 / 4) d$, and the maximum profit is $\pi_{m 1}^{\mathrm{SR} *}=(1 / 32) d^{2}, \pi_{m 2}^{\mathrm{SR} *}=(1 / 8) d^{2}, \pi_{m 3}^{\mathrm{SR} *}=(1 / 32) d^{2}$.

(2) S_R_Cheat Model. Similar to the analysis of the cheating behavior of the distributor under the price collusion between supplier and distributor, when they collude, the retailer obtains the motivation of cheating in the price collusion. At this time, the optimal marginal price of the supplier and distributor will be similar to that in the S_R_Collusion model, which is $p_{d 1}^{\mathrm{SR} *}=(1 / 8)$ $d, p_{d 2}^{\mathrm{SR} *}=(1 / 2) d$. Then, the decision making of the retailer's cheating behavior is to decide its new quotation $p_{3}$ based on the new profit function:

$$
\begin{aligned}
& \quad \pi_{d 3}^{\mathrm{SR}}=\max _{p_{3}} \pi_{3}\left(p_{d 1}^{S R *}, p_{d 2}^{S R *}, p_{3}\right), \\
& \text { s.t. } p_{i} \geq 0, \quad i=3 .
\end{aligned}
$$

Through the above objective function, we get the optimal marginal price of retailer $p_{d 3}^{S R *}=(3 / 16) d$, the optimal demand $q_{d 3}^{S R *}=(3 / 16) d$, and all the optimal profit $\pi_{d 1}^{S R *}=(3 / 128) d^{2}, \pi_{d 2}^{S R *}=(3 / 32) d^{2}, \pi_{d 3}^{S R *}=(9 / 256) d^{2}$.

According to the punishment mechanism of the CT in the Microeconomics, the critical discount factor can be solved as follows:

$$
\delta_{3}^{S R} \geq \delta_{3}^{S R *}=\frac{\pi_{d 3}^{S R *}-\pi_{m 3}^{S R *}}{\pi_{d 3}^{S R *}-\pi_{s 3}^{*}}=\frac{(9 / 256) d^{2}-(1 / 32) d^{2}}{(9 / 256) d^{2}-(1 / 64) d^{2}}=\frac{1}{5} .
$$

Proposition 5. In a three-echelon supply chain, the retailer's profits of price collusion, cheating, and Stackelberg game satisfy $\pi_{d 3}^{S R *}=(9 / 256) d^{2}>\pi_{m 3}^{S R *}=(1 / 32) d^{2}>\pi_{s 3}^{*}=(1 / 64) d^{2}$.

(1) When the discount factor satisfies $\delta_{3}^{S R} \geq \delta_{3}^{S R *}=(1 / 5)$, the supplier and retailer are likely to collude price to get higher loans the SCF service provider in the threeechelon trade-based SCF transaction structure.

(2) When the discount factor satisfies $\delta_{3}^{S R}<\delta_{3}^{S R *}=(1 / 5)$, the three-echelon trade-based SCF transaction structure has the ability to actively restrain price collusion, that is, self-restraint, which could effectively avoid the price collusion behavior.

Proof. It follows directly from the above analysis and is thus omitted.

5.2. Price Collusion under Simultaneous Game. Simultaneous game is similar to Cournot game in which the supplier, distributor, and retailer quote at the same time. According to CT, we analyze the simultaneous game, price collusion, and cheating behaviors of the supplier, distributor, and retailer in the three-echelon supply chain.

5.2.1. Benchmark Model: Simultaneous Game. Simultaneous game (similar to Cournot game) is a benchmark model for the supplier, distributor, and retailer to quote at the same time. According to CT, we first analyze the simultaneous game in the three-echelon supply chain and then the price collusion and cheating in three different forms of price collusion. When the supplier, distributor, and retailer play simultaneous game, the solution of reverse selection is as follows. First, the profit maximization of the supplier is

$$
\begin{aligned}
& \pi_{\text {Sim } 1}=\max _{p_{1}} \pi_{1}\left(p_{1}, p_{2}, p_{3}\right), \\
& \text { s.t. } p_{i} \geq 0, \quad i=1,2,3 .
\end{aligned}
$$

Therefore, the optimal reaction curve of supplier to the distributor and retailer's quotations is as follows:

$$
\begin{gathered}
\frac{d \pi_{1}\left(p_{1}, p_{2}, p_{3}\right)}{d p_{1}}=d-2 p_{1}-p_{2}-p_{3}=0 \\
p_{1}\left(p_{2}, p_{3}\right)=\frac{1}{2}\left(d-p_{2}-p_{3}\right) .
\end{gathered}
$$

Following the same principle, we could get $p_{2}\left(p_{1}, p_{3}\right)$ and $p_{3}\left(p_{1}, p_{2}\right)$. Then, we solve the above three reaction curves simultaneously, that is,

$$
\left\{\begin{array}{l}
p_{1}\left(p_{2}, p_{3}\right)=\frac{1}{2}\left(d-p_{2}-p_{3}\right), \\
p_{2}\left(p_{1}, p_{3}\right)=\frac{1}{2}\left(d-p_{1}-p_{3}\right), \\
p_{3}\left(p_{1}, p_{2}\right)=\frac{1}{2}\left(d-p_{1}-p_{2}\right) .
\end{array}\right.
$$

At last, we have $p_{1}^{*}=p_{2}^{*}=p_{3}^{*}=(1 / 4) d, q^{*}=(1 / 4) d$, and $\pi_{\text {Sim } 1}^{*}=\pi_{\text {Sim } 2}^{*}=\pi_{\text {Sim } 3}^{*}=(1 / 16) d^{2}$. 
5.2.2. All the Collusion and Cheating Scenarios under Simultaneous Game. Similar to Sections 5.1.2-5.1.4, we need to analyze all the price collusion and cheating behaviors between any two members in the three-echelon supply chain. To easily compare and analyze all the scenarios, we summarize the calculation results in all cases in Table 2.

Proposition 6. In a three-echelon supply chain with the supplier, distributor, and retailer, because anyone's profit under price collusion is equal to that under the simultaneous game, colluding price to get high loans is difficult under the simultaneous game.

According to the calculation results in Table 2, if the distributor and retailer or the supplier and retailer conduct price collusion, we cannot solve any discount factor based on CT because all the supply chain members' profit is equal whether in price collusion or in cheating scenarios. When the supplier and distributor conduct price collusion, the distributor's profit in cheating scenarios is higher than that in price collusion scenarios, but the profit in price collusion scenarios is equal to that in the simultaneous game. Therefore, the supplier and distributor cannot conduct price collusion.

\section{Comparative Analysis}

In this section, we conduct a comparative analysis of the optimal solutions among different games (i.e., sequential and simultaneous games) in different SCF transaction structures (i.e., two-echelon supply chain and three-echelon supply chain).

6.1. Sequential vs. Simultaneous Game in Two-Echelon Supply Chain. We comparatively analyze and summarize all the optimal marginal prices, demands, and maximum profits of the supplier and retailer with price collusion and cheating behavior in sequential game and simultaneous game. The results are shown in Table 3.

Under the sequential game, when supplier and retailer collude price, the profits of suppliers remain unchanged, but the profits of retailer and the actual market demand increase significantly. The retailer's profit when cheating from the price collusion is higher than that when conducting price collusion, whereas the supplier's is the opposite. From another perspective, considering the advantages of retailer as the buyer's market power, the supplier is likely to be willing to cooperate with retailer in price collusion without damaging their own profits. Of course, if the supplier's product is a best seller and there is no lack of consumer market, the opposite may be true. Under the simultaneous game, both the supplier and retailer's profit when conducting price collusion is higher than that in the simultaneous base game, but only the retailer's profit when cheating from the price collusion is higher than that in price collusion.

Proposition 7. In a two-echelon supply chain, the discount factor under the simultaneous game is higher than that under the sequential (Stackelberg) game, i.e., $\delta_{\text {Sim }}^{*}=(9 / 17)>(1 / 5)=\delta_{\text {Seq }}^{*}$, which means the supplier and retailer are more likely to conduct price collusion to get high loans under the sequential game.

The above proposition shows that the price collusion stability in the simultaneous game is lower than that in sequential game because both the profits of supplier and retailer in the simultaneous game are higher. Without doubt, the partners involved in the price collusion under the simultaneous game are more likely to cheating. At the same time, the simultaneous game in two-echelon SCF transaction structure can more effectively avoid price collusion and control the risk of SCF than sequential game.

6.2. Two-Echelon vs. Three-Echelon Supply Chain. We comparatively analyze and summarize all the optimal marginal prices, demands, and maximum profits of supplier, distributor, and retailer with price collusion and cheating behavior in the three-echelon supply chain under the sequential game. All the scenarios in the three-echelon supply chain under the simultaneous game are shown in Table 2, and those in the two-echelon supply chain are presented in Table 4. Therefore, we will not repeat them here.

According to the above comparative analysis, we reach the following detailed conclusions.

\section{Observation 1.}

(1) In the two-echelon supply chain, there is a greater risk of price collusion to obtain higher loans from the SCF service provider.

(i) Under the sequential game

(I) If the discount factor $\delta_{\mathrm{Seq}}^{*} \geq(1 / 5)$, it is easy to conduct price collusion; otherwise, if $\delta_{\text {Seq }}^{*}<(1 / 5)$, the supply chain can effectively avoid the price collusion behavior.

(II) As the supplier's profit (or revenue charged from the retailer) does not change $\pi_{s 1}^{\text {Seq* }}=\pi_{m 1}^{\text {Seq* }}$, the retailer cannot conduct price collusion to get higher loans.

(II )Under the simultaneous game

(I) If the discount factor $\delta_{\text {Sim }}^{*} \geq(9 / 17)$, it is easy to conduct price collusion; otherwise, if $\delta_{\text {Sim }}^{*}<(9 / 17)$, the supply chain can effectively avoid the price collusion behavior.

(II) As the supplier's profit (or revenue charged from the retailer) has increased from the price collusion $\pi_{c 1}^{S i m *}<\pi_{m 1}^{S i m *}$, the retailer can get higher loans from the SCF service provider.

(2) In the three-echelon supply chain, there is a small risk of price collusion to obtain higher loans from the SCF service provider.

(i) Under the sequential game

(i) If

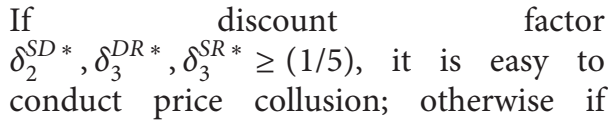




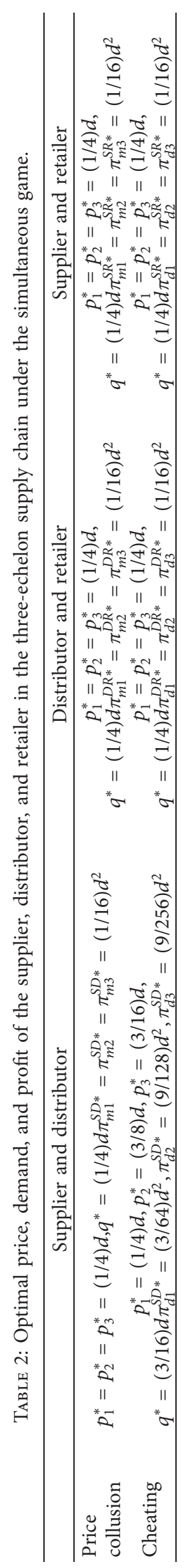


TABLE 3: Optimal price, demand, and profit of the supplier and retailer in the two-echelon supply chain.

\begin{tabular}{|c|c|c|c|c|}
\hline & Price & Demand & Profit & $\delta$ \\
\hline $\begin{array}{l}\text { Seq } \\
\text { Sim }\end{array}$ & $\begin{array}{l}p_{s 1}^{\text {Seq* }}>p_{m 1}^{\text {Seq* }}=p_{d 1}^{\text {Seq* }} p_{s 2}^{\text {Seq* }}=p_{m 2}^{\text {Seq* }}<p_{d 2}^{\text {Seq* }} \\
p_{c 1}^{\text {Sim* }}>p_{m 1}^{\text {Sim } *}=p_{d 1}^{\text {Sim* }} p_{m 2}^{\text {Sim } *}<p_{c 2}^{\text {Sim } *}<p_{d 2}^{\text {Sim } *}\end{array}$ & $\begin{aligned} & q_{s}^{\text {Seq }} *<q_{d}^{\text {Seq* }}<q_{m}^{\text {Seq } *} \\
& q_{c}^{\text {Sim * }}<q_{d}^{\text {Sim } *}<q_{m}^{\text {Sim } *}\end{aligned}$ & $\begin{array}{c}\pi_{s 1}^{\text {Seq* }}=\pi_{m 1}^{\text {Seq }}>\pi_{d 1}^{\text {Seq } *} \pi_{s 2}^{\text {Seq* }}<\pi_{m 2}^{\text {Seq* }}<\pi_{d 2}^{\text {Seq* }} \\
\pi_{m 1}^{\text {Sim* }}>\pi_{c 1}^{\text {Sim* }}>\pi_{d 1}^{\text {Sim }} \pi_{c 2}^{\text {Sim* }}<\pi_{m 2}^{\text {Sim* }}<\pi_{d 2}^{\text {Sim } *}\end{array}$ & $\begin{array}{c}\delta_{\text {Seq }}^{*}=(1 / 5) \\
\delta_{\text {Sim }}^{*}=(9 / 17)\end{array}$ \\
\hline
\end{tabular}

Seq represents the sequential game, and Sim represents the simultaneous game.

$\delta_{2}^{S D *}, \delta_{3}^{D R *}, \delta_{3}^{S R *}<(1 / 5)$, the supply chain can effectively avoid the price collusion behavior.

(II) As the supplier's (or distributor's) profit (or revenue charged from the distributor or retailer) does not change $\pi_{s 1}^{*}=\pi_{m 1}^{S D *}, \pi_{s 2}^{*}=$ $\pi_{m 2}^{D R *}$ in S_D_Collusion and D_R_Collusion, the distributor (or retailer) cannot conduct price collusion to get higher loans.

(II;i) As the distributor's profit (or revenue charged from the retailer) has increased $\pi_{s 2}^{*}<\pi_{m 2}^{S R *}$ from the price collusion in S_R_Collusion, the retailer can get higher loans from the SCF service provider. However, at this time, the supplier and the retailer are in price collusion and need the cooperation of the distributor to conduct this kind of price collusion to obtain higher loans from the SCF service provider. In most cases, this is impossible.

(II; ) Under the simultaneous game

(I) Seeing that anyone's profit in price collusion is equal to that under the simultaneous game, conducting price collusion to get high loans is difficult under the simultaneous game (see Proposition 6).

\section{Extension}

In Section 4, the analysis is based on the assumption of complete information and the equal profit allocation between the supplier and retailer in the two-echelon supply chain. In this section, we expand the analysis from two aspects. First, the profits are distributed according to sharing factors. Second, price collusion behavior is analyzed under incomplete information.

7.1. Revenue Sharing. Although the average allocation of the profits may seem fair, such is not always the case because some people value the relative value and others value the absolute value. That is, some firms value the profits of each other. Therefore, we develop the sharing factors to make it lean toward the general sense [39]. We assume that the two individuals involved in the price collusion behavior share the total profits of the price collusion according to a certain sharing factors $\left(\gamma_{1}, \gamma_{2}\right)$ and satisfy $\gamma_{1}+\gamma_{2}=1$. We expect to find a suitable proportionality portfolio $\left(\gamma_{1}^{*}, \gamma_{2}^{*}\right)$ to allocate the profit of price collusion or concentrate decision-making profit, supplemented by the restrictive constraints of the critical discount factor $\delta \geq \delta^{*}$. In fact, it is equivalent to finding a coordinated contract combination $\left(\gamma_{1}^{*}, \gamma_{2}^{*}, \delta \geq \delta^{*}\right)$ to achieve supply chain coordination and obtain the maximum profit of the whole supply chain.

As the whole profit of the price collusion is $\pi^{*}=(1 / 4) d^{2}$, the retailer shares the collusion profit as $\pi_{m}=$ $(1 / 4) \gamma_{2} d^{2}, \gamma_{2} \in[0,1]$ and thus

$$
\delta \geq \delta^{*}=\frac{\pi_{d}-\pi_{m}}{\pi_{d}-\pi_{s}}=\frac{(9 / 64) d^{2}-(8 / 64) \gamma_{2} d^{2}}{(9 / 64) d^{2}-(4 / 64) d^{2}}=\frac{9}{5}-\frac{16}{5} \gamma_{2}
$$

Because $\delta \in[0,1], \quad 0 \leq(9 / 5)-(16 / 5) \gamma_{2} \leq 1$, that is, $(4 / 16) \leq \gamma_{2} \leq(9 / 16)$. Therefore, the above combination contract form $\left(\gamma_{1}^{*}, \gamma_{2}^{*}, \delta \geq \delta^{*}\right)$ can be expressed as follows:

$$
D^{*}=\left\{\begin{array}{l}
\delta \geq \delta^{*}=\frac{9}{5}-\frac{16}{5} \gamma_{2}^{*}, \\
\gamma_{2}^{*} \in\left[\frac{4}{16}, \frac{9}{16}\right], \quad \delta \in[0,1], \\
\gamma_{1}^{*}+\gamma_{2}^{*}=1 .
\end{array}\right.
$$

We refer to the above combination as a combined contract, which is based on the following considerations. For the sequential game in the two-echelon supply chain, the leader can be either a supplier or a retailer. If the supplier is a leader, it belongs to the category of price leadership. If the retailer is a leader, it is essentially the category of output leadership, especially when the supplier, as leader, wants to establish strategic partnership with retailer and even performs vertical integration, that is, forward integration. To prevent retailer from collusion in the supply chain, the above combined contracts can be selected as a necessary regulatory measure. As described in the book "Intermediate Microeconomics: A Modern Approach [2]," when the long-term sequential game could be used as a punishment "threat" for price collusion, we can prove that the above regulatory measures are effective.

Proposition 8. In a two-echelon supply chain under the sequential game with revenue sharing factor $\left(\gamma_{1}, \gamma_{2}\right)$, the profits of supply chain in price collusion, cheating, and sequential game, respectively, are $\pi_{m}=(8 / 64) \gamma_{2} d^{2}, \pi_{d}=(9 / 64) d^{2}$, and $\pi_{s}=(4 / 64) d^{2}$.

(1) When the revenue sharing factor and the critical discount factor satisfy $\left(\gamma_{1}^{*}, \gamma_{2}^{*}, \delta^{*}\right) \in \mathscr{R}^{3} \backslash D^{*}$, the twoechelon trade-based SCF transaction structure has the ability to actively restrain price collusion, that is, selfrestraint, which can effectively avoid the price collusion behavior $\left(\mathscr{R}^{3}=[0,1] \times[0,1] \times[0,1]\right)$. 


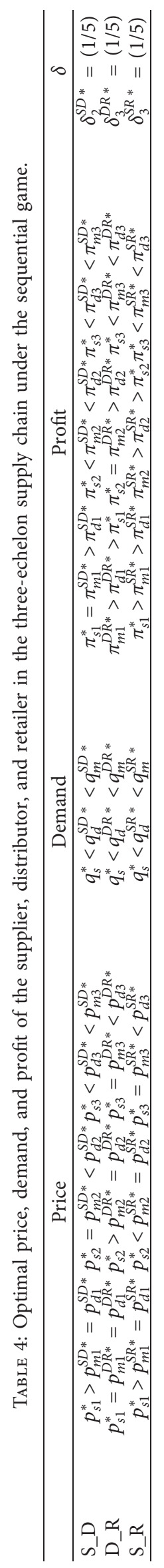


(2) When the revenue sharing factor and the critical discount factor satisfy $\left(\gamma_{1}^{*}, \gamma_{2}^{*}, \delta^{*}\right) \in D^{*}$, the supplier and the retailer can easily conduct price collusion to get higher loans from the SCF service provider. To control this risk of SCF, we should let the revenue sharing and critical discount factor combination strategy belong to $\mathscr{R}^{3} \backslash D^{*}$.

Proof. It follows directly from the above analysis and is thus omitted.

7.2. Incomplete Information. The above analysis ignores that when we assume that one partner cheating, the other partner may cheat at the same time, which is expanded here. When considering cheating in the price collusion, the supplier thinks that the retailer may maintain the quotations of price collusion or may also cheat in the price collusion. Therefore, it is ideal to assume that the retailer will be cheating in the price collusion with a certain probability $\varepsilon_{2}$. Similarly, the retailer will also make the above considerations, assuming that the probability of cheating of the supplier is $\varepsilon_{1}$.

According to the previous analysis process, if the supplier and the retailer cheat at the same time, their cheating quotations satisfy $p_{1}^{*}=p_{2}^{*}=(3 / 8) d$. At this time, their profits satisfy $\pi_{1}^{*}=\pi_{2}^{*}=(6 / 64) d^{2}$ (see Figure 4.). Obviously, the profits of the supplier and retailer who cheat at the same time are lower than the profits in price collusion, which is not what they want.

When only one of the suppliers and retailers is cheating in the price collusion, the critical discount factor is $\delta_{c}^{*}=(9 / 17)$. When they are cheating at the same time, the critical discount factor at this time satisfies $\delta_{c}^{*}=0$ because the profit of cheating does not meet their respective interests (see Figure 4). Based on the above analysis and the probability distribution of possible cheating behavior, the following propositions can be obtained.

Proposition 9. In a two-echelon supply chain under the simultaneous game with the probability of cheating of the supplier and retailer $\left(\varepsilon_{1}, \varepsilon_{2}\right)$, the profits of price collusion, only one cheating, both cheating, and simultaneous game, respectively, are $\pi_{m}=(8 / 64) d^{2}, \pi_{i}^{d}=(9 / 64) d^{2}, \pi_{d}=(6 / 64) d^{2}$, and $\pi_{i}^{c}=(1 / 9) d^{2}, i=1,2$.

(1) The probability of both the supplier and retailer cheating together from the price collusion is $\varepsilon_{1} \times \varepsilon_{2}$. At this time, if the critical discount factor satisfies $\delta \geq \delta_{c}^{*}=0$, in most cases, the supplier and retailer are likely to conduct price collusion to get higher loans from the SCF service provider in the trade-based SCF transaction structure.

(2) The probability of either only the supplier or only the retailer cheating from the price collusion is $\left(1-\varepsilon_{1}\right) \varepsilon_{2}+\left(1-\varepsilon_{2}\right) \varepsilon_{1}$. At this time, if the critical discount factor satisfies $\delta \geq \delta_{c}^{*}=(9 / 17)$, the supplier and retailer are likely to conduct price collusion to get higher loans from the SCF service provider. However, if the discount factor satisfies $\delta \geq \delta_{c}^{*}=(9 / 17)$, the

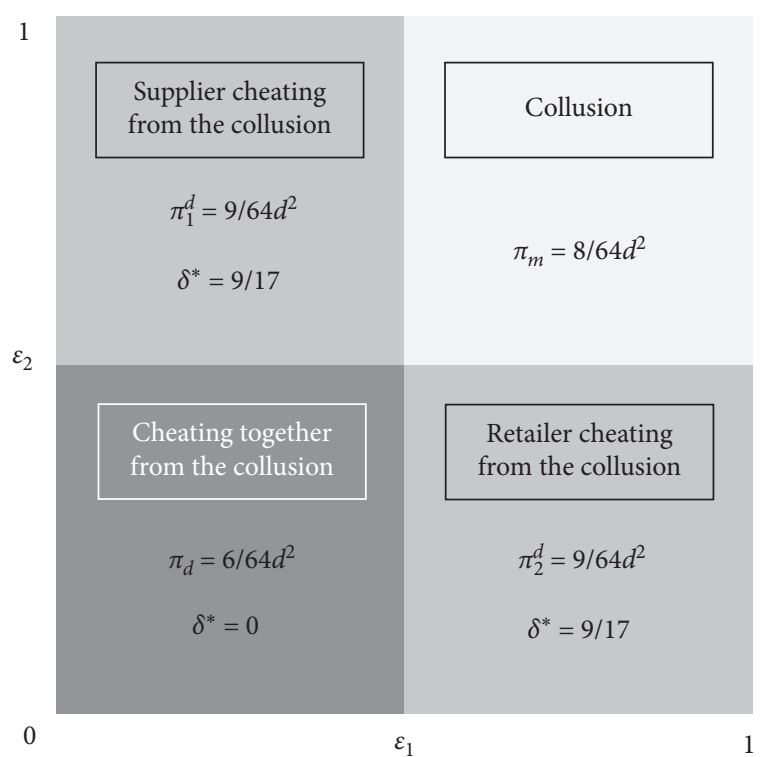

Figure 4: Cheating in the price collusion.

trade-based SCF transaction structure has the ability to actively restrain price collusion, that is, self-restraint, which can effectively avoid the price collusion behavior.

(3) The probability of neither the supplier nor the retailer cheating from the price collusion is $\left(1-\varepsilon_{1}\right)\left(1-\varepsilon_{2}\right)$. At this point, no matter what the critical discount factor is, the supplier and retailer are likely to conduct price collusion to get higher loans from the SCF service provider.

Proof. It follows directly from the above analysis and is thus omitted.

Under the background of the simultaneous game, both the supplier and retailer may cheat in the price collusion at the same time because of the simultaneous quotation, so the critical discount factor depends on the probability of cheating.

Next, we analyze the size of the critical discount factor in both simultaneous and sequential games.

We

construct $\delta\left(\varepsilon_{1}, \varepsilon_{2}\right)=\delta_{c}^{*}-\delta_{s}^{*}=(9 / 17)\left[\left(1-\varepsilon_{1}\right) \varepsilon_{2}+\left(1-\varepsilon_{2}\right) \varepsilon_{1}\right]-(1 / 5)$, where $\delta_{c}^{*}=(9 / 17)\left[\left(1-\varepsilon_{1}\right) \varepsilon_{2}+\left(1-\varepsilon_{2}\right) \varepsilon_{1}\right]$.

The positive and negative conditions of $\delta\left(\varepsilon_{1}, \varepsilon_{2}\right)$ are analyzed by numerical simulation with MATLAB. If it is positive, then the price collusion stability in the simultaneous game is lower than the stability in the sequential game, and vice versa. A negative sign of $\delta\left(\varepsilon_{1}, \varepsilon_{2}\right)$ indicates that the collusion stability in the simultaneous game is higher than that in sequential game.

Looking at the different directions of the following figure, $\delta\left(\varepsilon_{1}, \varepsilon_{2}\right)$ can be positive or negative (see Figure 5). In two different game situations, the probability assumptions that the supplier and retailer may be cheating change the absolute superiority and inferiority of critical discount factors. The more realistic relationships between the critical discount factors should be relative to the combination 


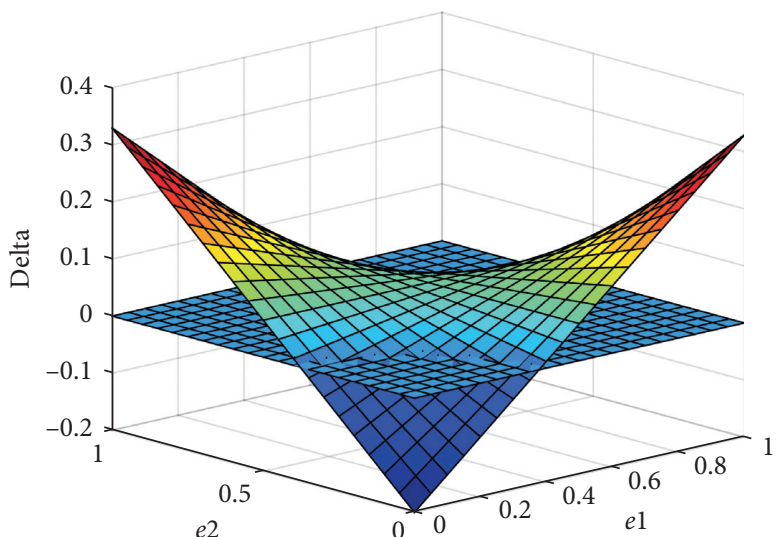

(a)

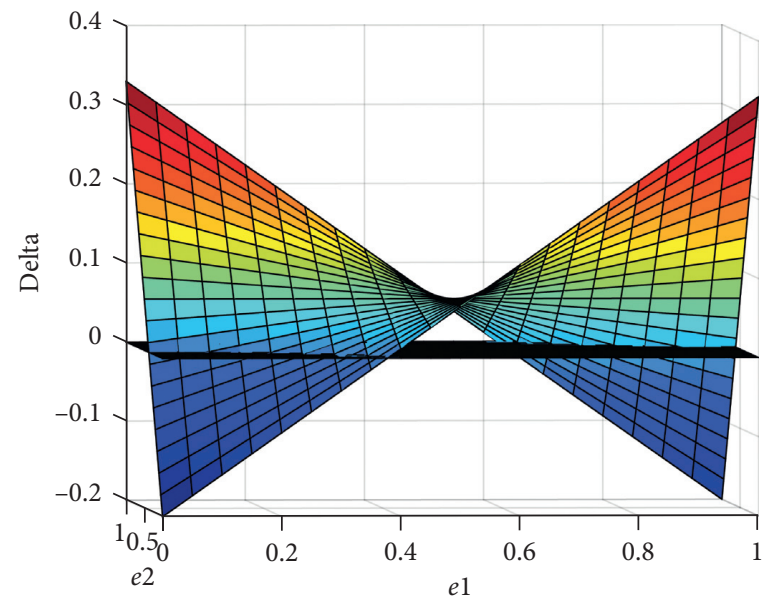

(c)

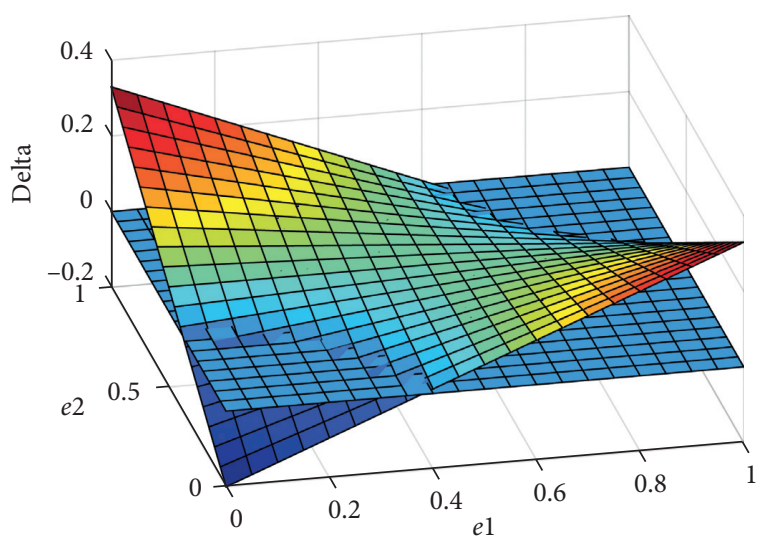

(b)

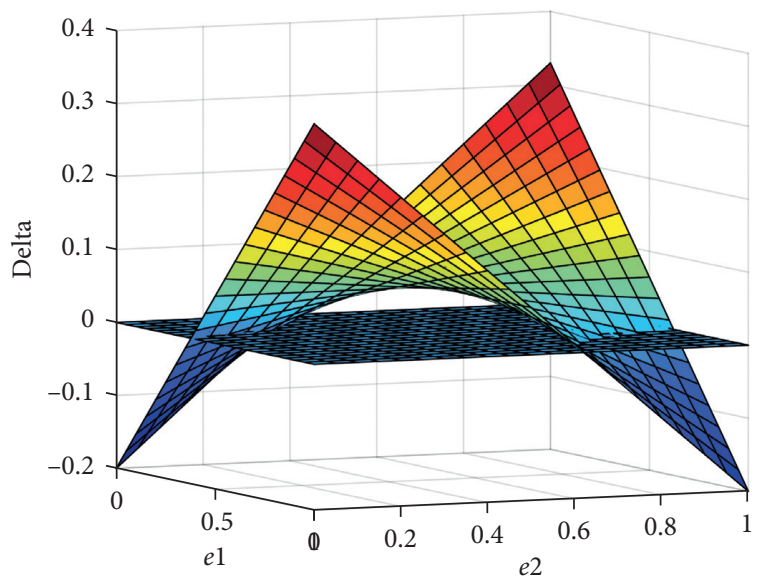

(d)

FiguRE 5: Size relationship (the $x$ label $e 1$ represents $\varepsilon_{1} ; y$ label $e 2$ represents $\varepsilon_{2}$; and z label delta represents $\delta$ ).

probability $\delta\left(\varepsilon_{1}, \varepsilon_{2}\right)$ of cheating. In absolute sense, there are no absolute advantages or disadvantages relationship because it is almost impossible to achieve complete information symmetry in reality.

By observing the above figure, we can summarize the relationship between the size relation between the two critical discount factors and the combined probability $\left(\varepsilon_{1}, \varepsilon_{2}\right)$ as shown in Figure 6, where $\varepsilon_{1}\left(\varepsilon_{2}\right)=(17 / 45)-\left((11 / 45) /\left(1 / \varepsilon_{2}\right)-2\right)$.

\section{Observation 2.}

(1) In the probability of both the supplier and retailer cheating in the price collusion $P_{r} \in \mathrm{I} \cup \mathrm{III}$, the critical discount factor satisfies $\delta_{c}^{*}<\delta_{s}^{*}$, and the twoechelon supply chain under the simultaneous game is much more likely to conduct price collusion to get higher loans from the SCF service provider than that in sequential game.

(2) In the probability of both the supplier and retailer cheating in the price collusion $P_{r} \in \mathrm{II}$, the critical discount factor satisfies $\delta_{c}^{*} \geq \delta_{s}^{*}$, and the two-echelon supply chain with one supplier and one retailer

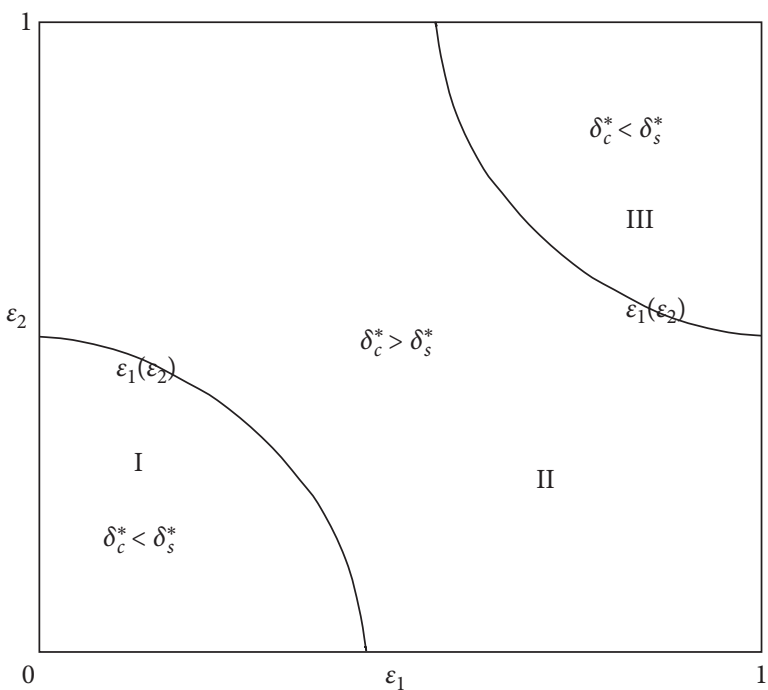

FIgURE 6: Size relationship.

under the sequential game is much more likely to conduct price collusion to get higher loans from the SCF service provider than that in the simultaneous game. 


\section{Theoretical and Managerial Implications}

8.1. Theoretical Implications. Theoretically, this study can provide a new research direction for integrating SCF and price collusion behavior in microeconomics. Although SCF can help supply chain solve the capital limitation problem, price collusion is a very big risk for the customers, whole supply chain, and financial systems. Studies on the price collusion behavior in SCF are very limited. We look forward to providing reference values for the design of SCF transaction structure to effectively avoid the price collusion behavior. A large amount of related research can be conducted in the future along such a research direction. As shown in Figure 7 , it constitutes an implementation manual for effective prevention of the price collusion risks in the SCF transaction structure.

This paper provides a solution to avoid the price collusion behavior in SCF. We develop various game models to identify the boundary conditions of price collusion in the different trade-based SCF transaction structures. Then, the results of these models are compared and analyzed to confirm the advantages and disadvantages of different SCF transaction structures on preventing price collusion behavior.

From game model results, we identify influence factors to avoid price collusion. First, SCF transaction structure has an important influence on price collusion behavior. The three-echelon supply chain experiences more difficulties to form price collusion behavior to get higher loans than the two-echelon supply chain. Second, critical discount factor can be adopted to prevent price collusion behavior. Therefore, financial institutions should take corresponding measures to improve the discount factor. Third, the profit sharing and incomplete information also affect the price collusion behavior. This paper develops two types of mechanism, profit sharing and incomplete information, to restrain price collusion.

8.2. Managerial Implications. This section illustrates the managerial implications of this study through two cases, from two-echelon supply chain to three-echelon SCF transaction structure, to effectively control the financial risk of supply chain.

8.2.1. Case Study 1: Xiangyu Co., Ltd vs. JG Group. Xiangyu Co., Ltd. (stock code: 600057) is a supply chain company focusing on bulk commodity procurement, distribution, terminals, logistics, and park development. The company's business philosophy is "create value of the circulation and service for the company's growth." It services an industrial chain, relying on the scientific and advanced management information system, experienced professional operation team, and efficient and rigorous risk control system, with a sound market network, perfect logistics facilities, and good corporate reputation. It provides customers with the full value chain distribution services from the purchasing and supplying of the raw and auxiliary materials and semifinished products to the distribution of finished products. Xiangyu Co., Ltd. assists customers to systematically and comprehensively plan, organize, coordinate, and control the business flow, logistics, capital flow, and information flow throughout the entire process. It also helps the companies of manufacturing and distribution to build the core competitiveness of the supply chain in all directions. In 2018, the company achieved an operating revenue of 234 billion yuan, which is expected to reach 300 billion yuan in 2019 .

Jinguang Group is the only large-scale enterprise group with complete stainless steel industrial chain in southwest China and the first private enterprise to complete the entire stainless steel production chain. Jinguang Group has a production capacity of 1.5 million tons of stainless steel smelting and hot rolling and 0.3 million tons of cold-rolled sheet, with an annual sales revenue of more than 20 billion yuan (see Figure 8 ).

Since 2015, due to the state's macroeconomic policy of regulating steel production capacity, although stainless steel does not belong to the category of traditional steel, stainless steel products are still in short in supply and spot cash transactions, but Jinguang Group is still unable to escape from the bank's loan withdrawal behavior. With its comprehensive service capabilities in logistics and supply chain management, Xiangyu Co., Ltd., has been deeply rooted in the stainless steel industry for many years, providing many customers with SCF services, such as raw material procurement, finished product distribution and receivables, and payable accounts financing. In this context, Xiangyu Co., Ltd., chose to cooperate with Jinguang Group to provide raw material agency procurement, finished product distribution, and financing services. At the same time, through the reengineering of business processes, Xiangyu Co., Ltd., helped Jinguang Group achieve a substantial reduction of its inventory-occupying funds from 2 billion yuan to 600 million yuan and provided SCF services with a total credit line of 600 million yuan. At this time, the two sides' trading agency relationship is a typical two-echelon SCF transaction structure. According to our study on this type of transaction structure design, there is an invisible loophole in which fraud collusion occurs. Shortly after the cooperation between the two parties, the project operators of the two sides colluded, resulting in the fund repayment risks of tens of millions (similar to the case of Luckin Coffee Inc. (NASDAQ: LK)). Therefore, the two sides decided to reform the transaction structure after several rounds of consultations. Local governments took the lead in establishing the stateowned platform company. From the perspective of SCF transaction structure, the platform company is located in the middle of Xiangyu and Jinguang Group. The platform company provides agency procurement and distribution services for the Jinguang Group. Xiangyu shares the platform company's procurement and distribution services, which constitutes a typical three-echelon SCF transaction structure (see Figure 9). According to our research conclusions, we can see spontaneous constraints on the collusion behavior in the three-echelon SCF transaction structure, which can effectively avoid the occurrence of collusion. At the same time, as the main sponsor of the 


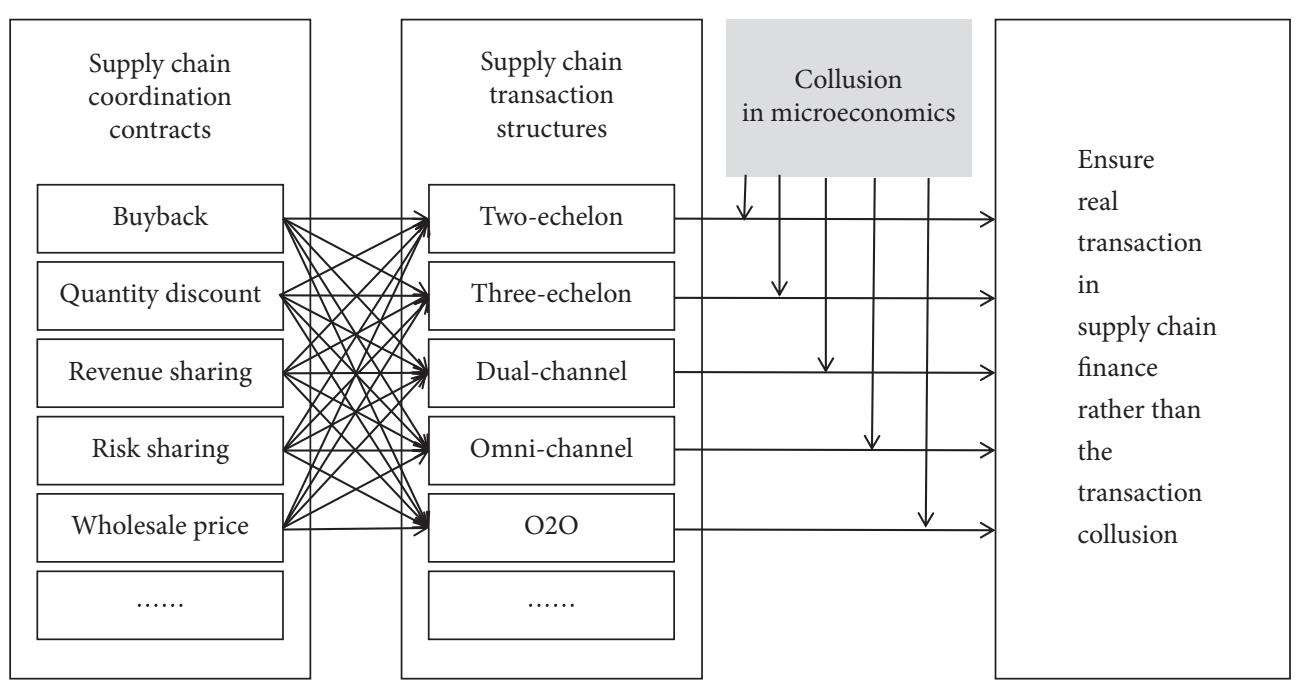

FIgURE 7: Research directions.

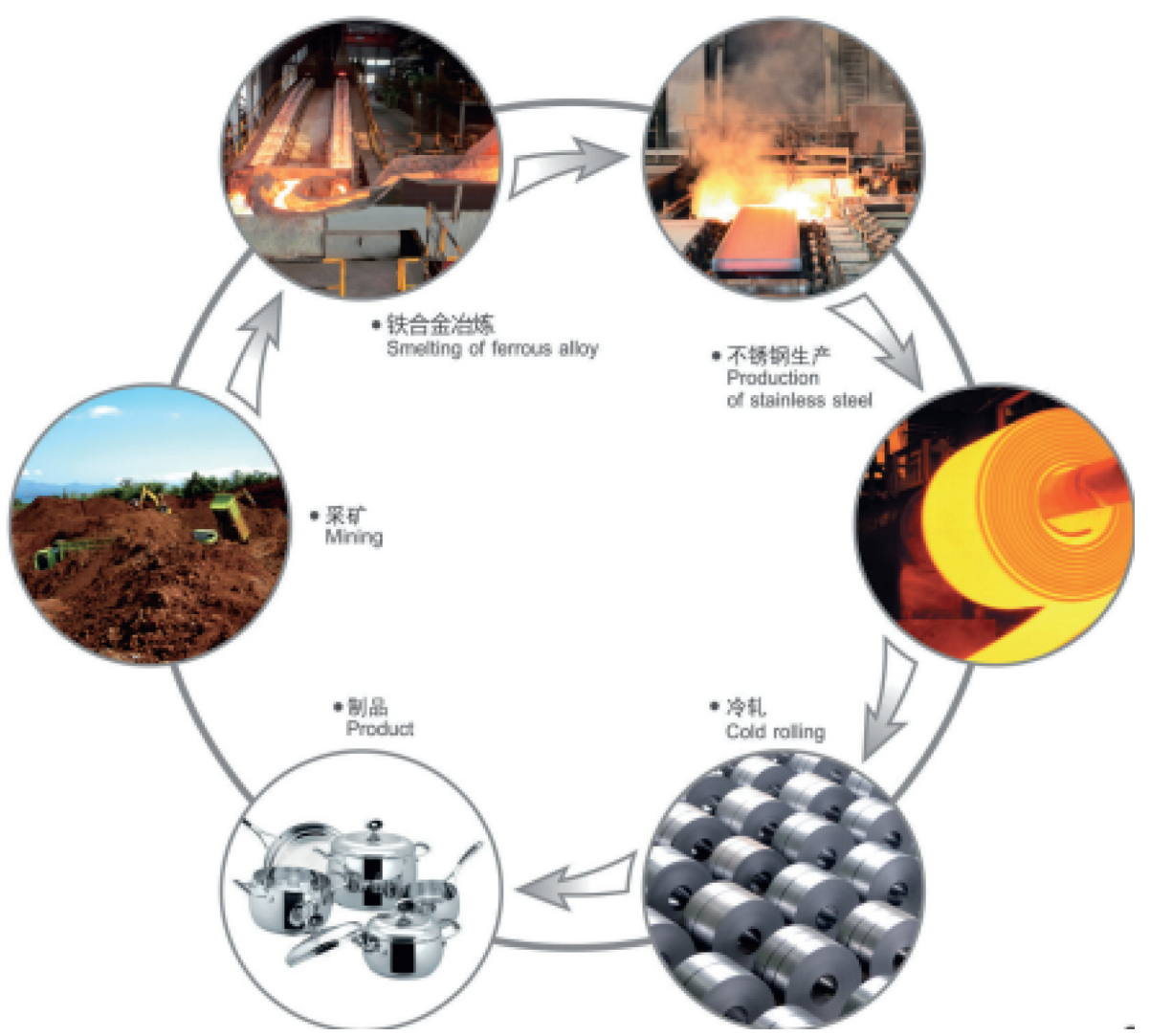

FIgURE 8: Whole supply chain of Jinguang Group.

platform company, the government has played the role of supervision and deterrence, further enhancing the security and stability of the SCF services.

\subsubsection{Case Study 2: Sichuan Logistics and Sichuan Railway} Logistics Co., Ltd. Both the Sichuan Logistics and Sichuan Railway Logistics Co., Ltd., are typical kind of "supply chain pallet company," which provide the trade-based supply chain finance service. To control the risk of SCF service, they must change the supply chain transaction structure. For example, if there is a supplier purchasing coal and supplying it to the power company, and it is capital constraint. The supplier wants to get supply chain finance loans from this kind of "supply chain pallet company," such as the Sichuan Logistics Co., LTD, and the supply chain transaction structure must be changed to as follows. The supplier purchases the coal, supplies it to the Sichuan Logistics Co., 


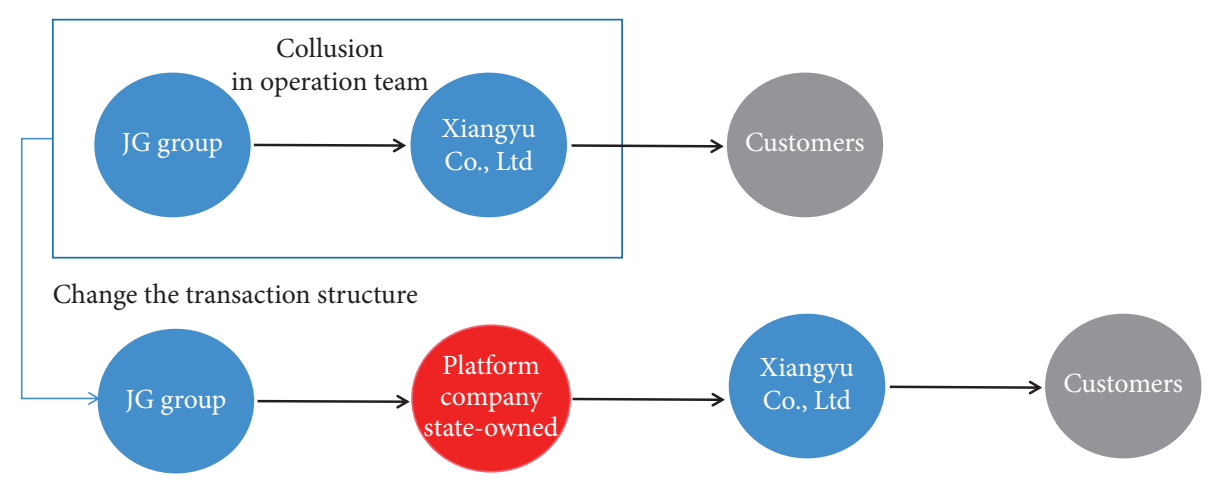

FIgURE 9: Changing of the transaction structure.

Table 5: Other case companies.

\begin{tabular}{|c|c|c|c|c|}
\hline No. & Company (stock code) & Main business & $\begin{array}{l}\text { Income ( } 100 \\
\text { million yuan) }\end{array}$ & $\begin{array}{l}\text { Market value (100 } \\
\text { million yuan) }\end{array}$ \\
\hline 1 & $\begin{array}{l}\text { Wuchan Zhongda Group Co., } \\
\text { Ltd. (600704) }\end{array}$ & $\begin{array}{l}\text { Metal materials, chemicals, coal, vehicles, mineral } \\
\text { products, finance, logistics, etc. }\end{array}$ & $\begin{array}{c}3589.22 \\
(2020,1-12)\end{array}$ & 239.4 \\
\hline 2 & $\begin{array}{l}\text { Xiamen International Trade } \\
\text { Group Co., Ltd. (600755) }\end{array}$ & $\begin{array}{l}\text { Supply chain management business, financial services, real } \\
\text { estate operations, etc. }\end{array}$ & $2262(2020,1-9)$ & 127.90 \\
\hline 3 & Eternal Asia (002183) & $\begin{array}{l}380 \text { distribution platform, global procurement platform, } \\
\text { logistics platform, Yushang Financial Control platform, etc. }\end{array}$ & $436.6(2020,1-9)$ & 95.52 \\
\hline 4 & $\begin{array}{l}\text { CCS Supply Chain } \\
\text { Management Co., Ltd. (600180) }\end{array}$ & $\begin{array}{l}\text { Bulk commodities supply chain, bulk commodities e- } \\
\text { commerce platform and supply chain finance, etc. }\end{array}$ & $264.23(2020,1-9)$ & 55.80 \\
\hline 5 & $\begin{array}{l}\text { CMST Development Co., Ltd. } \\
\text { (600787) }\end{array}$ & Commodity circulation, transportation, finance, etc. & $332.7(2020,1-9)$ & 111.53 \\
\hline
\end{tabular}

Ltd., and then the Sichuan Logistics Co., Ltd., and supplies it to the power company. Through this kind of supply chain transaction structure change, the supply chain finance service provider, such as the Sichuan Logistics and Sichuan Railway Logistics Co., LTD, can restrain the collusion between the supplier and the downstream company. Other similar listed companies are shown in Table 5.

\section{Conclusions, Limitations, and Future Research}

Price collusion, which is different from supply chain integration, does great harm to SCF to obtain higher financial loans. We investigate the impact of SCF transaction structures on price collusion behavior under different game models in the two-echelon and three-echelon supply chain. Finally, we develop two types of mechanism, profit sharing and incomplete information, to restraint the price collusion. Through this research, we arrive at a series of interesting conclusions for price collusion in SCF.

In the two-echelon supply chain, the supplier's original leader's preemptive pricing advantage becomes a disadvantage when cheating may occur in the price collusion under the sequential game. In this kind of game, it is almost impossible for the supplier to cheating because the cheating behavior of the supplier can be found by the retailer in one game. The cheating behavior of retailers may be discovered by supplier at least twice in the game process. When our hypothesis changes to simultaneous game, suppliers and retailers may also cheat, and the price collusion stability in the simultaneous game is lower than that in the sequential game. When suppliers and retailers perform the simultaneous game, the profits of both sides are higher than the sequential game, so they are more likely to cheat.

In the three-echelon supply chain, there is no interest basis for any price collusion between any parties, and the SCF transaction structure has spontaneous endogenous constraints on price collusion. In the practice of SCF business, we should give priority to the three-level SCF transaction structure with self-restraint ability as the service object. In this transaction structure, we can use relatively loose revenue sharing and key discount factors. However, for the supply chain that may have price collusion, the financing threshold should be raised, such as using constraint mechanism (a key discount factor) to effectively control the financing risk of the supply chain.

This paper mainly studies the existence and stability of price collusion in a two-echelon or three-echelon supply chain without any supply chain coordination strategy under the assumption of completely rational economic person. The research shows a possible domain space for price collusion in the two-echelon supply chain, and external measures should be taken to avoid price collusion. There is no feasible price collusion in the three-echelon supply chain, and the transaction structure is binding on the price collusion spontaneously, that is, self-restraint. In the future, in the context of more extensive supply chain coordination strategies, such as buyback, quantity discount, revenue sharing, and risk sharing, the price collusion behavior in different types of SCF transaction structures should be 
analyzed and distinguished to provide decision support and in-depth insights into the actual business environment for SCF practice. At the same time, we need to compare and analyze the price collusion behavior under different market demand structures to eliminate the dependence of research results on specific models as much as possible.

\section{Data Availability}

All data in the article are available from the authors upon reasonable request.

\section{Conflicts of Interest}

The authors declare no conflicts of interest.

\section{Acknowledgments}

This research was supported by Fundamental Research Funds for the Central Universities (JBK1507105) and National Natural Science Foundation of China Project (72072021 and 71772032).

\section{References}

[1] X. Fan and Y. J. Chen, "Contracts in a procurement supply chain with intermediation: combating collusion in price competition," Naval Research Logistics (NRL), 2020.

[2] H. R. Varian, Intermediate Microeconomics A Modern Approach, W. W. Norton \& Co., New York, NY, USA, 6th edition, 2003.

[3] X. Fu and G. Tan, "Abuse of market dominance under China's anti-monopoly law: the case of tetra pak," Review of Industrial Organization, vol. 54, no. 2, pp. 409-434, 2019.

[4] T. Economist, "No truck with cartels, the economist," 2016, https://www.economist.com/news/business/21699957expensive-times-companies-accused-collusion-no-truckcartels..

[5] X. Xu, X. Chen, F. Jia, S. Brown, Y. Gong, and Y. Xu, "Supply chain finance: a systematic literature review and bibliometric analysis," International Journal of Production Economics, vol. 204, pp. 160-173, 2018.

[6] Y. Wang, "Chinese court freezes shareholding of steel-trading king," 2014, https://www.forbes.com/sites/ywang/2014/02/08/ chinese-court-freezes-shareholding-of-steel-trading-king/? $\mathrm{sh}=1$ ef $47 \mathrm{~d} 4710 \mathrm{ba}$.

[7] F. Abraham and L. L. P. Twersky, "Luckin coffee inc. (NASDAQ:LK) investor alert: abraham, fruchter \& twersky, llp announces investigation of securities fraud claims globenewswire," 2020, https://www.globenewswire.com/ news-release /2020/04/02/2011174/0/en/LUCKIN-COFFEEINC-NASDAQ-LK-INVESTOR-ALERT-Abraham-FruchterTwersky-LLP-Announces-Investigation-of-Securities-FraudClaims.html.

[8] A. Chmelar, "Transaction Banking: respecting its role in the real economy," ECRI Policy Brief, vol. 6, no. 6, 2013.

[9] E. Fenmore, "Making purchase-order financing work for you," Secured Lender, vol. 60, no. 2, p. 20, 2004.

[10] E. Hofmann, "Inventory financing in supply chains," International Journal of Physical Distribution \& Logistics Management, vol. 39, no. 9, pp. 716-740, 2009.
[11] L. Chen, S. Yao, and K. Zhu, "Responsible sourcing under supplier-auditor collusion," Manufacturing \& Service Operations Management, vol. 22, no. 6, 2020.

[12] H. Wu, N. Su, C. Ma, P. Liao, and D. Li, "A privacy protection solution based on NLPCA for blockchain supply chain financial system," International Journal of Financial Engineering, vol. 07, no. 03, Article ID 2050019, 2020.

[13] J. Bian, K. K. Lai, Z. Hua, X. Zhao, and G. Zhou, "Bertrand vs. Cournot competition in distribution channels with upstream collusion," International Journal of Production Economics, vol. 204, pp. 278-289, 2018.

[14] J. Miklós-Thal and C. Tucker, "Collusion by algorithm: does better demand prediction facilitate coordination between sellers?" Management Science, vol. 65, no. 4, pp. 1552-1561, 2019.

[15] D. A. Wuttke, C. Blome, H. Sebastian Heese, and M. Protopappa-Sieke, "Supply chain finance: optimal introduction and adoption decisions," International Journal of Production Economics, vol. 178, pp. 72-81, 2016.

[16] J. S. Heywood and Z. Wang, "Profitable collusion on costs: a spatial model," Journal of Economics, vol. 131, no. 3, pp. 267-286, 2020.

[17] W. Dou, X. Liu, and L. An, "Ownership concentration, allocation of control rights and inefficient investment in firms: monitoring or colluding among multiple large shareholders," Journal of Management Sciences in China, vol. 14, no. 11, pp. 81-96, 2011.

[18] B. M. Overvest, "A note on collusion and resale price maintenance," European Journal of Law and Economics, vol. 34, no. 1, pp. 235-239, 2012.

[19] M. P. Schinkel and Y. Spiegel, "Can collusion promote sustainable consumption and production?" International Journal of Industrial Organization, vol. 53, pp. 371-398, 2017.

[20] X. Zhao, K. Yeung, Q. Huang, and X. Song, "Improving the predictability of business failure of supply chain finance clients by using external big dataset," Industrial Management \& Data Systems, vol. 115, no. 9, pp. 1683-1703, 2015.

[21] S. Piccolo and M. Reisinger, "Exclusive territories and manufacturers' collusion," Management Science, vol. 57, no. 7, pp. 1250-1266, 2011.

[22] T. Melkonyan, H. Zeitoun, and N. Chater, "Collusion in Bertrand vs. Cournot competition: a virtual bargaining approach," Management Science, vol. 64, no. 12, 2017.

[23] X. Zheng, L. Sun, and A. A. Tsay, "Distribution channel strategies and retailer collusion in a supply chain with multiple retailers," Asia-Pacific Journal of Operational Research, vol. 35, no. 3, 2018.

[24] Q. Wang, X. Hong, and Y Gong, "Collusion or not: the optimal choice of competing retailers in a closed-loop supply chain," International Journal of Production Economics, vol. 225, Article ID 107580, 2020.

[25] C. Bai, K. Govindan, A. Satir, and H. Yan, "A novel fuzzy reference-neighborhood rough set approach for green supplier development practices," Annals of Operations Research, pp. 1-35, 2019.

[26] B. Huo, "The impact of supply chain integration on company performance: an organizational capability perspective," Supply Chain Management: An International Journal, vol. 17, no. 6, pp. 596-610, 2012.

[27] Q. Zhu, H. Krikke, and M. C. Caniels, "Supply chain integration: value creation through managing inter-organizational learning," International Journal of Operations \& Production Management, vol. 38, no. 1, 2018. 
[28] Y. Zhu, L. Zhou, C. Xie, G. J. Wang, and T. V. Nguyen, "Forecasting SMEs' credit risk in supply chain finance with an enhanced hybrid ensemble machine learning approach," International Journal of Production Economics, vol. 211, pp. 22-33, 2019.

[29] R. J. Saulnier and N. H. Jacoby, The Development of Accounts Receivable Financing, Nber Chapters, Cambridge, MA, USA, 1943.

[30] M. B. Wessman, "Purchase money inventory financing: the case for limited cross-collateralization," The Ohio State Law Journal, vol. 51, no. 3, pp. 1283-1447, 1990.

[31] X. Chen and A. Wang, "Trade credit contract with limited liability in the supply chain with budget constraints," Annals of Operations Research, vol. 196, pp. 153-165, 2012.

[32] C. H. Lee and B. D. Rhee, "Trade credit for supply chain coordination," European Journal of Operational Research, vol. 214, no. 1, pp. 136-146, 2011.

[33] D. Seifert, R. W. Seifert, and M. Protopappa-Sieke, “A review of trade credit literature: opportunities for research in operations," European Journal of Operational Research, vol. 231, no. 2, pp. 245-256, 2013.

[34] H. H. Lee, J. Zhou, and J. Wang, "Trade credit financing under competition and its impact on firm performance in supply chains," Manufacturing \& Service Operations Management, vol. 20, no. 1, pp. 36-52, 2017.

[35] H. Peura, S. A. Yang, and G. Lai, "Trade credit in competition: a horizontal benefit," Manufacturing \& Service Operations Management, vol. 19, no. 2, pp. 263-289, 2017.

[36] J. Martin and E. Hofmann, "Involving financial service providers in supply chain finance practices: company needs and service requirements," Journal of Applied Accounting Research, vol. 18, no. 1, pp. 42-62, 2017.

[37] H. Song, K. Yu, A. Ganguly, and R. Turson, "Supply chain network, information sharing and SME credit quality," Industrial Management \& Data Systems, vol. 116, no. 4, pp. 740-758, 2016.

[38] C. H. Loch and Y. Wu, "Social preferences and supply chain performance: an experimental study," Management Science, vol. 54, no. 11, pp. 1835-1849, 2008.

[39] C. Bai and J. Sarkis, "Supplier development investment strategies: a game theoretic evaluation," Annals of Operations Research, vol. 240, no. 2, pp. 583-615, 2016. 